\title{
Recent Developments in the Immobilization of Palladium Complexes on Renewable Polysaccharides for Suzuki-Miyaura Cross-Coupling of Halobenzenes and Phenylboronic Acids
}

\author{
Adi Wolfson * and Oshrat Levy-Ontman * \\ Department of Chemical Engineering, Sami Shamoon College of Engineering, Basel/Bialik Sts., \\ Beer-Sheva 8410001, Israel \\ * Correspondence: adiw@sce.ac.il (A.W.); oshrale@sce.ac.il (O.L.-O.)
}

Received: 23 December 2019; Accepted: 15 January 2020; Published: 18 January 2020

check for updates

\begin{abstract}
Polysaccharides derived from natural sources exhibit unique structures and functional groups, which have recently garnered them increased attention for their potential applicability as supports for metal catalysts. Renewable polysaccharide matrices were employed as supports for palladium complexes, with or without previous modification of the support, and were used in Suzuki cross-coupling of halobenzenes and phenylboronic acid derivatives. In this review, recent developments in the immobilization of palladium-based complexes are reported, including descriptions of the preparation procedures and catalytic activity of each system. In addition, the effects of the nature of the polymeric support and of the reaction conditions on catalytic performance are discussed.
\end{abstract}

Keywords: cross-coupling; heterogeneous catalysts; immobilization; palladium; polysaccharides Suzuki-Miyaura

\section{Introduction}

\subsection{Coupling Reactions}

Coupling reactions, wherein two different components interact in the presence of a catalyst to form a new bond, represent a highly important class of reactions in organic chemistry. Constituting a powerful and useful organic synthesis tool, coupling reactions enable complex molecules to be synthesized from simple precursors. They are therefore widely used in industry, especially in the production of fine chemicals [1,2].

In general, coupling reactions can be categorized according to two main types, homo-coupling and cross-coupling, which refer to the interaction of two similar, and two different, molecules, respectively. Moreover, catalytic cross-coupling reactions of organometallic reagents with organic electrophiles are often employed for the synthesis of a wide range of $\mathrm{C}-\mathrm{C}, \mathrm{C}-\mathrm{H}, \mathrm{C}-\mathrm{N}, \mathrm{C}-\mathrm{O}, \mathrm{C}-\mathrm{S}, \mathrm{C}-\mathrm{P}$, or C-M bonds [3]. As mentioned before, these reactions proceed in the presence of different catalysts, among which palladium-based catalysts have been shown to have the widest applicability.

Suzuki-Miyaura Cross-Coupling

Though a variety of organometallics can be used in C-C cross-coupling reactions with aryl halides, the higher activity and the relatively lower toxicity of organoborons or boronic acid derivatives, and their ease of synthesis and use, have rendered them attractive for use in the Suzuki or Suzuki-Miyaura cross-coupling reaction [4-6]. Since its introduction in 1979 by Akira Suzuki et al. [7], the Suzuki 
cross-coupling of halobenzenes and organoborons (Figure 1) (which earned Akira Suzuki the Nobel Prize in 2010), was successfully performed with numerous homogeneous and heterogeneous palladium-based catalysts, with the addition of a base as co-catalyst [4-12]. Although palladium was the main target metal of many research efforts and various industrial cross-coupling protocols, other metals like nickel [13-15], iron [16,17] rhodium [18-20], and copper [21], were also found to be active in Suzuki cross-coupling, and their applications in that context were thus investigated. In the last two decades, many homogeneous complexes and heterogeneous catalysts were synthesized and tested for their suitability in the Suzuki reaction. A wide variety of aryl halides and organoborons, and especially phenylboronic acid derivatives, were eventually tested, yielding a range of different activities [4-21]. Another class of Suzuki reaction is Acyl Suzuki cross-coupling; This reaction involves the coupling of an organoboron with an acylelectrophile, which replaces the holabenzenes, i.e., arylhalides in the traditional Suzuki reaction [22-25]. A classic, widely used Suzuki C-C cross-coupling reaction is represented in Figure 1.<smiles>[R]c1ccc([X])cc1</smiles><smiles>[R]c1ccc([SeH])cc1</smiles>
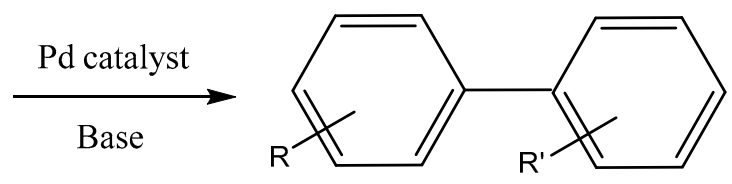

$$
\mathrm{X}=\mathrm{I}, \mathrm{Br}, \mathrm{Cl}
$$

Figure 1. Suzuki cross-coupling of halobenzene and phenylboronic acid derivatives.

The catalytic cycle of the Suzuki reaction with palladium catalysts (1) (Figure 2) comprises four steps: (a) oxidative addition of organic halides, $\mathrm{R}_{2}-\mathrm{X}(2)$, to $\mathrm{Pd}(0)$, to yield organopalladium species, $\mathrm{R}_{2}-\mathrm{Pd}(\mathrm{II})-\mathrm{X}$ (3); (b) removal of the halide by a base, for instance, $\mathrm{NaOH}$, which acts as a co-catalyst to form $\mathrm{R}_{2}-\mathrm{Pd}(\mathrm{II})-\mathrm{OH}(4)$; (c) transmetalation between $\mathrm{R}_{2}-\mathrm{Pd}(\mathrm{II})-\mathrm{OH}$ and $\mathrm{R}_{1}-\mathrm{B}(\mathrm{OH})_{3}{ }^{-}$(6), which was produced by the reaction of the organoboron $\mathrm{R}_{1}-\mathrm{B}(\mathrm{OH})_{2}(5)$ and the base to form the intermediate $R_{2}-P d(I I)-R_{1}(8)$; and (d) reductive elimination, which releases the product, $R_{1}-R_{2}$ (9), to regenerate the catalyst.

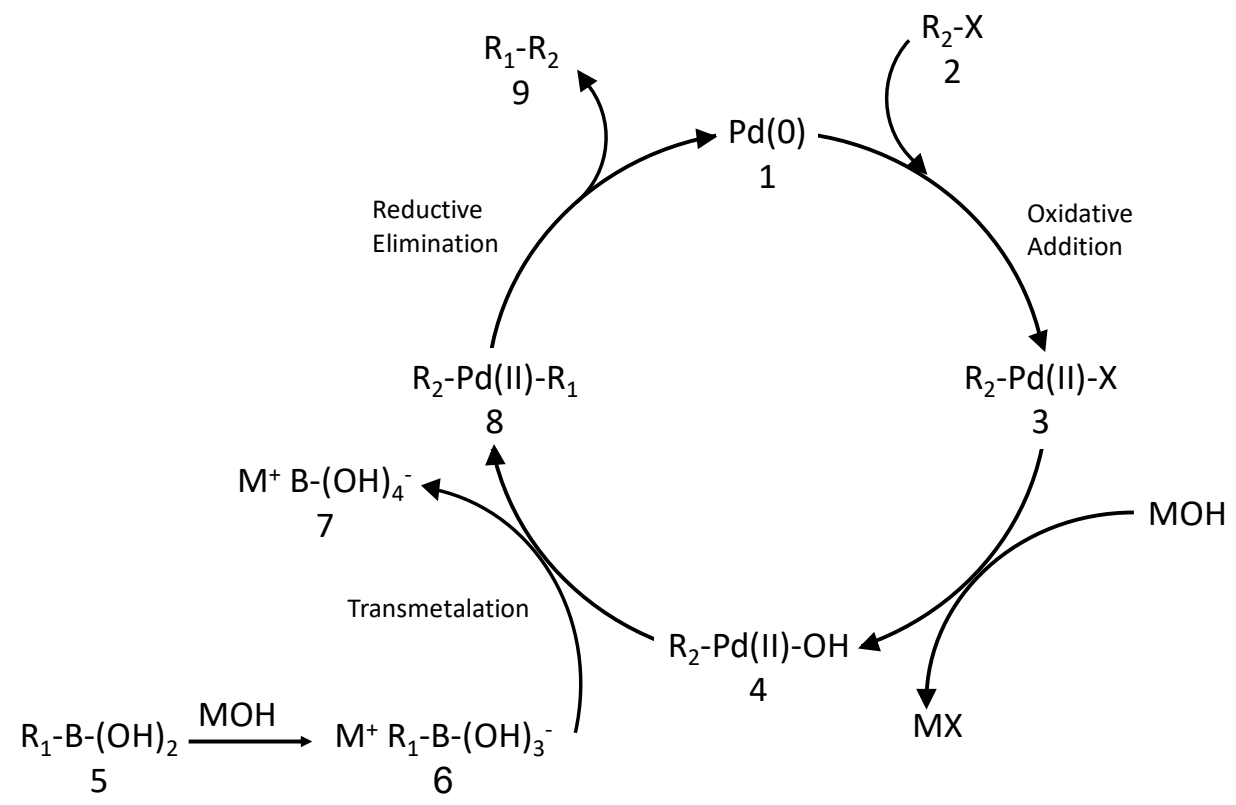

Figure 2. Mechanism of the Suzuki reaction catalytic cycle. 
In general, simple soluble palladium salts, like palladium chloride or palladium acetate [26], can activate the Suzuki reaction. Yet they are usually reduced under reaction conditions and form palladium black, which is less active. The addition of a ligand, usually a phosphine-based ligand [27,28] or $N$-heterocyclic carbine ligand [29,30], not only stabilizes the palladium center, but sometimes it also activates it. Despite the finding that palladium complexes were highly active in Suzuki reactions, their widespread use is effectively precluded by their tedious separation protocol and their lack of recyclability. Alternatively, numerous heterogeneous palladium-based catalysts, which can be easily recovered and recycled, were found to be very efficient in the Suzuki reaction. These heterogeneous systems are usually prepared by deposition of a palladium salt on a highly porous support that has a large surface area, which is then reduced to yield simple supported $\mathrm{Pd}(0)$ catalysts, like $\mathrm{Pd} / \mathrm{C}$ [31], palladium on silica [32] or Pd/Y zeolite [33]. Likewise, palladium nanoparticles, which are prepared from a palladium salt, a reducing agent and a stabilizer, can be fixed on variety of supports, from oxides, charcoals, or zeolites to polymers [34-36].

The Suzuki reaction can be performed with different halobenzenes and phenylboronic acid derivatives. Usually iodobenzenes are more active than, or have the same activity as, bromobenzenes, while chlorobenzenes are much less active. Furthermore, the addition to the halogen of electron withdrawal groups in the ortho or para positions increases its reactivity in oxidative addition compared to those halogens with electron-donating groups.

Finally, the development of environmentally benign and clean synthetic methods in organic transformation have drawn high attention in the recent years. For example, it includes the use of green solvents [37], such as water and ionic liquids, the exploitation of solventless reactions, and the use of microwave heating [38]. Therefore, the Suzuki cross-coupling reaction was tested in different solvents, some greener like water or ionic liquids, and some without a solvent at all, by using either conventional heating $(\mathrm{CV})$ or microwave irradiation $(\mathrm{MW})$.

\subsection{Heterogenization of Palladium Catalysts}

Another route to prepare highly efficient, recoverable, and recyclable catalytic systems is to combine the advantages of heterogeneous catalysts (easy recycling, good stability) with those of their homogeneous counterparts (high activity and selectivity) via heterogenization of the complex [39-41]. The heterogenization of homogeneous complexes has been studied extensively with the goal of elucidating a simple technique for the preparation of an efficient and as generally applicable as possible catalyst that will exhibit minimal leaching, thereby allowing it to be easily separated from the reaction mixture after the reaction, and recycled. In general, complex heterogenization can occur via chemical immobilization, by ionic or covalent bond, or via physical occlusion or entrapment within a support. Different organic and inorganic supports, such as polymers (e.g., polyvinyl alcohol and polydimethylsiloxane) and oxides (e.g., silica, alumina, zirconia and zeolite), have been reported in the literature as being suitable for use in heterogenization [39-41] and in biphasic systems [42-44]. The progress in the field notwithstanding, the widespread application of metal-supported catalysis is meanwhile precluded by slow reaction rates due to mass transfer limitations, narrow substrate scopes, a lack of reproducibility, high costs, and the often tedious heterogenization procedures. These drawbacks are the reason why most catalytic systems prepared by heterogenization have not been applied in industrial applications [45,46].

All of the above-mentioned heterogenization techniques have been exploited in the preparation of palladium-based catalysts for use in Suzuki cross-coupling. For instance, different palladium complexes were anchored to silica [47-49] or polymers [50-52], or they were used in biphasic systems with ionic liquids [53] or supported ionic liquids [54].

\subsection{Renewable Polysaccharides as Supports for Palladium Catalysts}

The immobilization of well-defined homogeneous catalysts on an either organic or inorganic solid support was already being investigated thirty years ago. Those efforts were driven by the premises that 
the approach can facilitate catalyst recycling and lead to reductions in the metal contamination of the organic products to render chemical processes that will be, overall, "greener" than those in use today. In recent decades, renewable and biodegradable organic polymers (i.e., natural biopolymers produced by various organisms) have attracted considerable attention for their use in practical applications across a diverse range of industries, including pharmaceuticals, biomedical products, cosmetics, and food; they are also applicable as fibers and building blocks in engineered materials [55-59]. The use of these biopolymers as supports for homogeneous metal-based catalysts is attractive for several reasons:

(1) The use of polysaccharides as insoluble supports allows for easy catalyst recycling, e.g., they are only negligibly soluble in organic solvents, even in highly polar and protic solvents, such as ethanol [60]. Moreover, they can form hydrogels, i.e., cross-linked polymeric networks to which are added different agents (e.g., metals or bases). Hydrogels have the capacity to swell with water, a significant fraction of which they retain in their structures, but they do not dissolve in aqueous media. Polysaccharides can also be used to form xerogels, which are dry, solid supports obtained when the liquid phase of a gel is removed by evaporation by various techniques.

(2) Insofar as they are obtained from renewable sources, they are considered safe, "green" components.

(3) The polysaccharides have a variety of different functional groups that can be fine-tuned to prepare efficient heterogeneous catalysts. In addition, they have many stereogenic centers that can induce asymmetry to catalytic processes.

An emerging class of biopolymers that has attracted significant attention due to their unique structures and functional groups comprises algae-derived polysaccharides, which include carrageenans $[61,62]$ and alginate $[63,64]$. In addition, chitosan-produced mainly by crustaceans such as crabs and shrimp and by fungi-was also employed $[65,66]$. Due to their unique structures and functional groups, natural polysaccharides were also used as supports for metal catalysts $[67,68]$. In the past decade, the preparation of polysaccharide-supported catalysts for organic reactions, with or without the modification of the support, has attracted increased attention [69]. These include, for example, chitosan [70-72] and carrageenans [73,74], which were also themselves used as catalysts, e.g., carrageenans with anionic sulfate groups in their structures were used as heterogeneous Lewis acid catalysts [74], and chitosan with added amine groups was used as a heterogeneous base in Michael addition [75].

Many renewable polysaccharides were also used to prepare, via different techniques, palladium-based heterogeneous catalysts. These catalysts were tested in different reactions, for instance, the substitution of allyl carbonate with morpholine was performed with polysaccharide aerogel microspheres that were used to support a thin water layer with a water-soluble palladium catalyst [76,77]. In another system, chitosan-supported palladium nanoparticles were tested for their ability to catalyze nitrophenol degradation [78], while nanoparticles of palladium supported on cellulose [79] or on agar/pectin [80] or agar [81] were tested in catalytic hydrogenations. Furthermore, palladium-based polysaccharide matrices were also synthesized and used in Heck coupling [82-85] and Suzuki coupling [86-89].

\subsection{Palladium-Based Polysaccharide Catalysts for Suzuki Cross-Coupling}

As previously noted, Suzuki cross-coupling can be catalyzed by either $\operatorname{Pd}(0)$ or $\operatorname{Pd}(\mathrm{II})$ species by using salts, complexes, and pure metal. These metal species can be heterogenized on organic and inorganic supports by immobilization, occlusion, or by using a supported liquid layer. Indeed, a range of palladium-based polysaccharide catalysts were synthesized and tested in the Suzuki cross-coupling reaction. Although some reviews that summarize different catalytic systems have also been published, they all screened the catalysts based on the type of the polysaccharide that was used as support while neglecting to compare the different catalyst preparations to each other [90-95].

The most straightforward route to immobilize palladium salts is to anchor the metal via the functional groups on the polymer backbone, e.g., amines or carboxylic acid. Alternatively, the polymer 
can also react with different ligands, e.g., a Schiff base, which then react with the metal ion to form a complex. In both methods, the resulting palladium species is $\mathrm{Pd}(\mathrm{II})$. In a second route, the palladium salt or complex that is mixed with the polysaccharide by diverse methods is reduced by different methods, e.g., using sodium borohydride or hydrogen, thus yielding $\operatorname{Pd}(0)$.

Various renewable polysaccharides were used to support palladium catalysts for Suzuki cross-coupling. The main characteristics of the polysaccharides that will discussed in the frame of this review are summarized in Table 1.

Table 1. Characteristics of the different renewable polysaccharides discussed in this review.

\begin{tabular}{|c|c|c|c|}
\hline Polysaccharide & Functional Groups & Branched/Linear & Building Block \\
\hline Chitosan & $\begin{array}{c}-\mathrm{NH}_{2} \\
-\mathrm{OH} \\
-\mathrm{NHCOCH}_{3}\end{array}$ & Linear & $\begin{array}{c}\beta(1,4)-N \text {-acetyl-D-glucosamine and } \\
\text { D-glucosamine }\end{array}$ \\
\hline Cellulose & $-\mathrm{OH}$ & Linear & $\beta$-(1 $\rightarrow 4)$-D-glucopyranose \\
\hline Hemicellulose & $\begin{array}{c}-\mathrm{COO}^{-} \\
-\mathrm{OH} \\
-\mathrm{CH}_{3} \mathrm{COOCH} \\
-\mathrm{CH}_{2} \mathrm{OH} \\
\end{array}$ & Branched & $\begin{array}{c}\text { Xylose } \beta \text { - }(1 \rightarrow 4) \text {-D-glucopyranose } \beta \text { - }(1 \rightarrow 4) \\
\text { Mannose } \beta \text { - }(1 \rightarrow 4) \text { glucopyranose } \\
\alpha 1-3 \text {-glucopyranose }\end{array}$ \\
\hline Starch & & Linear and Branched & $\begin{array}{l}\alpha 1-4 \text {-glucopyranose and } \\
\alpha 1-6) \text {-D-glucopyranose at the branch points }\end{array}$ \\
\hline Agar & $\begin{array}{l}-\mathrm{CH}_{2} \mathrm{OH} \\
-\mathrm{OH}\end{array}$ & Linear & $\begin{array}{l}\beta \text {-D-Gal and 3,6-anhydro- } \alpha \text {-D-Gal, which } \\
\text { alternate through } 1 \rightarrow 4 \text { and } 1 \rightarrow 3 \text { linkages }\end{array}$ \\
\hline Iota carrageenan & $\begin{array}{r}-\mathrm{OH} \\
-\mathrm{OSO}_{3}^{-}\end{array}$ & Linear & D-Gal-4-sulfate,3,6-anhydro-D-Gal-2-sulfate \\
\hline
\end{tabular}

As illustrated in Table 1, all the polysaccharides bear hydroxyl groups in their backbone, yet besides hydroxyl, the different polysaccharides also have other functional groups, such as amine groups (e.g., chitosan), carboxylic acids (e.g., hemicellulose), and sulfate groups (i.e., iota carrageenan). Not only do these groups determine the solubility of the polysaccharide in a solvent, they can also function as anchoring sites for metal salts or complexes. Besides being dependent on their functional groups and composition, the nature of a polysaccharide is also dependent on its molecular weight and three-dimensional structure $[94,96]$. Lastly, the presence of hydroxyl groups in all polysaccharides may lead to the formation of intra- and inter-molecular hydrogen bonds, while the addition of amine or sulfate groups to the sugar structure may result in the formation of stronger chemical bonds (i.e., amide and sulfate ester, correspondingly).

\section{Aims and Methodology}

This review comprises an overview of recent developments in the preparation of immobilized palladium catalysts based on renewable polysaccharides and assessments of the scope and limitations of the different catalytic systems in the Suzuki cross-coupling of halobenzenes with phenylboronic acid derivatives. As each palladium-based polysaccharide catalyst is prepared via a different method and tested under different conditions (e.g., solvent, temperature, substrate type and concentration, etc.) using a different technique (e.g., CV or MW), it was difficult to compare the performances of the various systems. Thus, the catalytic systems will be compared based on the heterogenization methodology and procedure (e.g., number of synthesis steps and preparation conditions), catalytic performance (e.g., reaction yields and the substrates spectrum), and the system's sustainability (e.g., catalyst synthesis, reaction conditions, and catalyst recycling). In this respect, some general concerns will be considered: (1) that the heterogenization procedure should be as simple as possible and reproducible; (2) that the leaching of the metal from the heterogenized catalyst should be minimal; (3) that the performance of the heterogeneous catalysts should be as close as possible to that of the parent catalyst; (4) that the separation of the heterogeneous catalyst from the reaction mixture, after the reaction, should be possible via simple filtration; and (5) that the heterogeneous catalyst should be easily reusable without 
a loss of activity. Furthermore, the effect of the nature of the polysaccharide on the heterogenization procedure and on catalytic performance will also be discussed.

\section{Literature Screening}

\subsection{Immobilization of Palladium Via a Schiff-Base}

In general, the immobilization of palladium complexes in polysaccharides was performed in several steps initiated with the anchoring of the ligand to the functional groups on the polymer and followed by the interaction of the palladium ions with the donor atoms of the ligand. One of the first and most commonly used renewable polysaccharides that was exploited to immobilize palladium complexes was chitosan. The prominence of chitosan in these initial catalyst immobilization attempts was mainly due to the amine groups it contains, which easily react with various organic molecules and serve as anchoring points. Hardy et al. [97] prepared a chitosan-pyridyl imine-based palladium catalyst in two steps: (1) mixing 2-pyridinecarboxaldehyde with chitosan in ethanol under reflux followed by the filtering and drying of the solid, and (2) addition of the solid to a palladium acetate $\left(\mathrm{Pd}(\mathrm{OAc})_{2}\right)$ solution in acetone and mixing followed by washing under reflux once each in ethanol, toluene, and acetonitrile, and then drying. In the resulting catalyst, the metal loading was $0.16 \mathrm{mmol} \cdot \mathrm{g}^{-1}$. Optimization studies of the reaction conditions in the Suzuki cross-coupling of bromobenzene and phenylboronic acid in $o$-xylene hinted that the optimum substrate:palladium molar ratio is 1200 , and no significant benefit was obtained when using larger amounts of catalyst, but increasing the reaction temperature to reflux $\left(143^{\circ} \mathrm{C}\right)$ significantly improved the yield. Under these optimal conditions, the catalyst yielded a conversion rate of $80 \%$ after $1 \mathrm{~h}$, and a minor increase in the conversion rate with time was observed ( $87 \%$ after $6 \mathrm{~h}$ ). The catalyst was also reused five times, each time following filtration and a simple wash with methanol, and in the fifth cycle, it yielded a $74 \%$ conversion rate after $1 \mathrm{~h}$. Furthermore, the new catalyst was also used with 10 other substrates, yielding relatively high conversions with bromo- and iodobenzenes, whereas only a $2 \%$ conversion was achieved with chlorobenzene.

Chitosan was also used in the preparation of four different palladium catalysts by Leonhardt et al. [98]. The first two catalysts were prepared by the dropwise addition of a hydrochloric aqueous solution of chitosan to a sodium hydroxide solution, which immediately formed beads that were then filtered, washed with water, and dried in air. While in the first system, palladium chloride $\left(\mathrm{PdCl}_{2}\right)$ was added to the chitosan solution before the precipitation (A1), in the second system, it was adsorbed to the dry beads (A2). Characterization of the different catalysts revealed that the beads of A1 and A2 had a diameter of approximately $2 \mathrm{~mm}$ and that they were not perfectly round. In addition, FTIR analyses showed that in these two systems, the palladium was mainly coordinated to the $\mathrm{N}$-atom on the amine groups in the chitosan backbone. XPS analysis of the A2 catalyst indicated the presence of $\operatorname{Pd}(\mathrm{II})$ species.

The two other chitosan-based palladium catalysts were prepared following the synthesis of a chitosan-Schiff base with salicylaldehyde (B) or with 2-pyridinecarboxaldehyde (C) (Figure 3), as in the system of Hardy et al. [97], under reflux in methanol or ethanol, respectively. At the end of the reaction, the solid was filtered, washed, and dried, after which it was added to a solution of palladium chloride (B1) or palladium acetate (C1), and then filtered, washed and dried again. In these chitosan-based palladium catalysts, the palladium was anchored via the phenol or the amine groups. XPS analyses of the two new catalysts, however, showed that the palladium occurred in two different oxidation states, $\operatorname{Pd}(\mathrm{II})$ and $\mathrm{Pd}(0)$, probably due to the catalyst being prepared in alcohol at air temperature, thus leading to a partial reduction of $\mathrm{Pd}(\mathrm{II})$ that was also favored by increased temperature.

The four catalysts were tested by using $o$-xylene and water as solvents under CV or MW conditions. As expected, the reaction in the MW regime proceeded much faster, producing high yields, up to $99 \%$ with both the A2 and B1 catalysts, after a few minutes (Table 2). In addition, the catalysts were 
also successfully recycled three times, after which the yields for catalysts A2 and B1 were somewhat reduced, while that for catalyst $\mathrm{C} 2$ even increased.
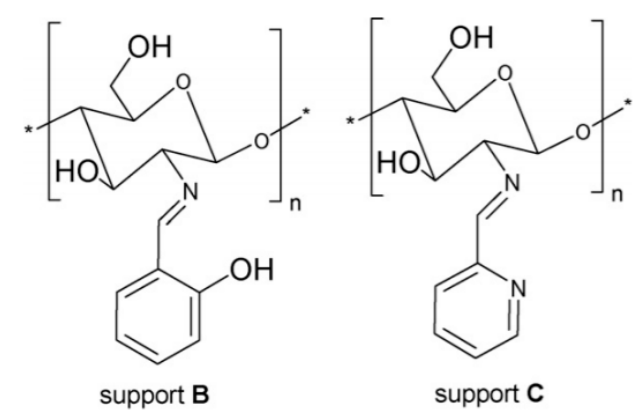

Figure 3. Structures of the modified chitosan supports of catalyst systems (B) (salicylaldehyde) and (C) (2-pyridinecarboxaldehyde). Adapted from ref. [98] with permission from Elsevier.

Table 2. Microwave-promoted Suzuki coupling reactions of $p$-bromophenol with phenylboronic acid in water ${ }^{a}$.

\begin{tabular}{ccccc}
\hline Catalyst & mol\% Pd & $\mathbf{t}(\mathbf{m i n})$ & Yield $\mathbf{( \% )}$ & Selectivity (\%) \\
\hline A1 & 0.12 & 10 & 58 & 97 \\
& 0.28 & 10 & 73 & 96 \\
A2 & 0.19 & 10 & $>99$ & $>99$ \\
& 0.19 & 5 & $>99$ & $>99$ \\
B1 & 0.2 & 10 & $>99$ & $>99$ \\
& 0.2 & 5 & $>99$ & $>99$ \\
C1 & 0.25 & 10 & 55 & 98 \\
& 0.48 & 10 & 45 & 95 \\
\hline
\end{tabular}

a Condition: $2 \mathrm{mmol}$ p-bromophenol, $2.1 \mathrm{mmol}$ phenylboronic acid, $8 \mathrm{mmol} \mathrm{Na} \mathrm{CO}_{3}, 4 \mathrm{~mL}$ water; microwave settings: $\mathrm{T}=150^{\circ} \mathrm{C}, \mathrm{Pmax}=400 \mathrm{~W}$.

In recent years, Talat Baran, in collaboration with various other researchers, has published extensive reports on the immobilization of palladium catalysts via different Schiff bases on different renewable polysaccharides. The various catalysts were characterized with FTIR to ensure that the formation of the Schiff base could be detected, and with EDAX and XRD to confirm the coordination of the palladium ion to yield the Pd(II) species. In addition, ICP-OES analysis was used to detect the palladium content, and TG/DTG analysis was employed to test the thermal stability of the new composite. SEM analysis was also used to study the surface morphology of the catalysts. Finally, the different catalysts were employed in Suzuki cross-coupling under optimized conditions, e.g., catalyst loading, type and amount of base and temperature, using different chloro-, bromo- and iodobenzenes with phenylboronic acid under microwave irradiation and without any solvent, and catalyst reuse was also tested.

Baran et al. [99] used chitosan that was reacted in water with mono-imine (the latter of which was previously synthesized via a condensation reaction between 2,4-pentadion and aminobenzoic acid in alcohol), and then reacted with an aqueous solution of $\mathrm{Na}_{2} \mathrm{PdCl}_{4}$ to yield two different palladium complexes, (a) OCMCS-3aPd and (b) OCMCS-4aPd (Figure 4).

The catalysts were tested in the Suzuki reaction, wherein yields up to $98 \%$ were obtained with aryl bromides while replacing the bromine with chlorine result in very low yields [99]. In addition, the two catalysts were recycled by using 4-bromoanisole and phenylboronic acid, and the yields were stable for three to four runs, after which they decreased from $98 \%$ to $75 \%$ in the tenth run.

Baran et al. [100] also prepared chitosan-Ulva beads (Ulva-biomass from green algae) by simply adding Ulva powder to an aqueous chitosan solution, stirring and then dropping the solution into an alkaline water-methanol coagulation solution to form beads. The beads were then incubated in the coagulation solution, filtrated, and washed with water. In the next step, the beads were transferred 
into a methanolic solution of glutaraldehyde and heated under reflux for cross-linking, then rinsed with water and dried at room temperature. Finally, the chitosan-Ulva composite bead was added together with $\mathrm{Na}_{2} \mathrm{PdCl}_{4}$ into water and stirred at room temperature. The yellow-brownish beads were recovered by filtration and washed with water to remove any uncomplexed ions and oven-dried to yield the chitosan-Ulva supported Pd(II) catalyst.

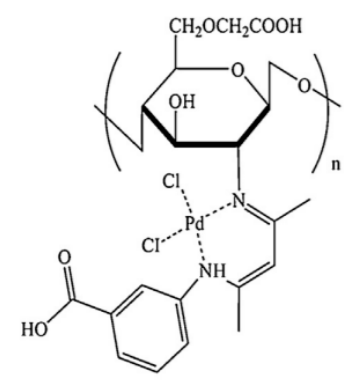

(a)

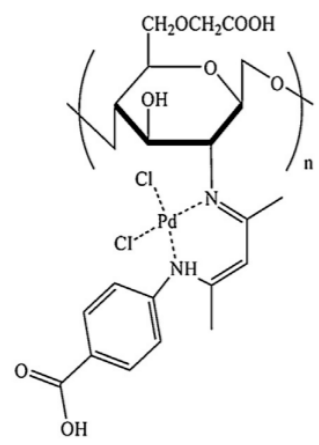

(b)

Figure 4. Chitosan Schiff-base-supported Pd(II) catalysts. (a) OCMCS-3aPd and (b) OCMCS-4aPd Adapted from ref. [99] with permission from Elsevier.

FTIR analysis of the new composite revealed that a Schiff base was formed via the cross-linking of chitosan, and that the palladium ions were coordinated to the nitrogen atoms of theses imine groups. The EDAX spectrum also confirmed this coordination, and both EDAX and ICP-OES analyses detected $\sim 20 \%$ palladium ion content.

The catalytic performance of chitosan-Ulva supported Pd(II) beads was tested in 14 different C-C coupling reactions using different chloro-, bromo- and iodobenzenes and phenylboronic acid under microwave irradiation, and high turnover frequencies (turnover frequency (TOF) $=$ yield of product/(mol Pd ${ }^{*}$ reaction time $\left.)\right)$, from $11,000 \mathrm{~h}^{-1}$ to $75,000 \mathrm{~h}^{-1}$, were obtained [100]. The catalyst was also tested for reusability for eight runs, and the yield of 4-methoxybiphenyl decreased from $99 \%$ to $83 \%$.

In another system [101], chitosan was synthesized with 2,2-pyridil to yield a chitosan-pyridil-based Pd(II) catalyst (Figure 5). In the first step, chitosan aqueous solution was prepared and then dropped into a coagulation solution containing methanol, water, and sodium hydroxide to obtain gelatinous chitosan beads. Then the chitosan beads were washed until neutrality with distilled water, after which they were transferred into a solution of 2,2-pyridil in ethanol and stirred under reflux before the beads were removed by filtration, washed with ethanol, and dried. In the second stage, an aqueous solution of $\mathrm{Na}_{2} \mathrm{PdCl}_{4}$ was added to a suspension of 2,2-pyridil cross-linked chitosan in water, stirred, filtrated out, and washed with water, yielding a chitosan-pyridil-based $\mathrm{Pd}(\mathrm{II})$ catalyst.

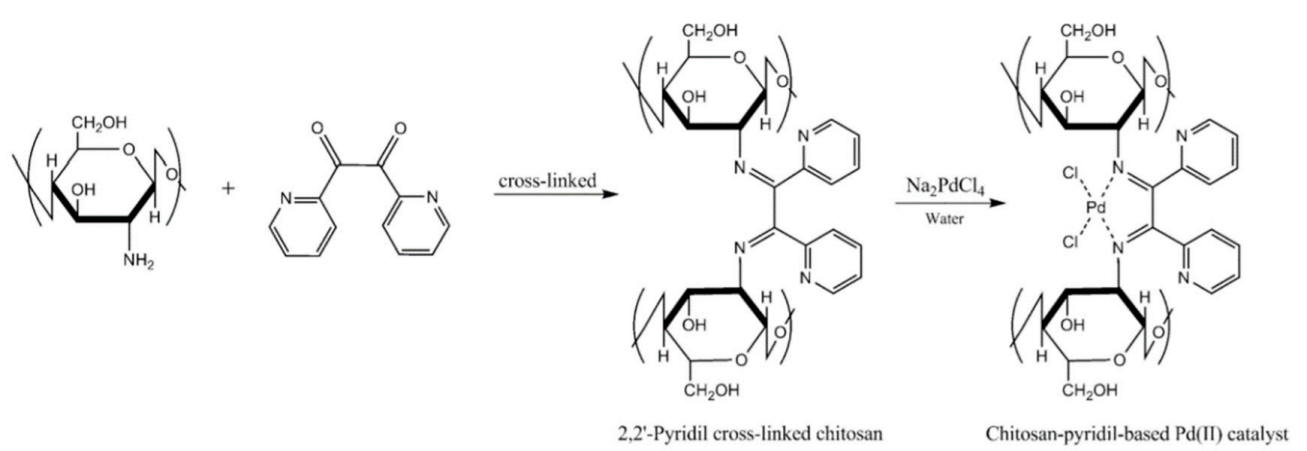

Figure 5. Chitosan-pyridil-based Pd(II) catalyst preparation. Adapted from ref. [101] with permission from Elsevier. 
FTIR confirmed the condensation of 2,2-pyridil with chitosan via the amino groups, and EDAX and XRD analyses verified the coordination of palladium ions to the 2,2-pyridil cross-linked chitosan [101]. The ICP-OES and EDAX analyses showed a $22 \%$ palladium content.

The performance of the catalyst in Suzuki cross-coupling, using different chloro-, bromo- and iodobenzenes and phenylboronic acid under microwave irradiation, yielded high TOFs, from 33,735 to $240,964 \mathrm{~h}^{-1}$ [101]. Performing the reaction with 4-bromoanisle under conventional heating resulted in 657 magnitude lower activity. The catalyst was also tested for reusability for seven runs, during which the yield of 4-methoxybiphenyl decreased from $99 \%$ to $75 \%$.

Recently, Baran also synthesized a new chitosan-Schiff-base-supported $\operatorname{Pd}(\mathrm{II})$ complex (Figure 6) [102]. Preparation of the complex started with the synthesis of (E)-2-((4-isopropylphenyl)imino)1,2-di(pyridin2-yl)ethanone (NSB) by stirring 2,2'-pyridil and 4-isopropyl aniline in ethanol. NSB was refluxed with chitosan in ethanol, then a solution of monochloroacetic in ethanol was added, and the reaction mixture was stirred for five days. The resulting CS-NNSB support that was obtained was dried, added to an aqueous solution of $\mathrm{Na}_{2} \mathrm{PdCl}_{4}$ that was stirred and then cooled, yielding CS-NNSB-Pd(II)), which was filtered from the reaction media and dried.

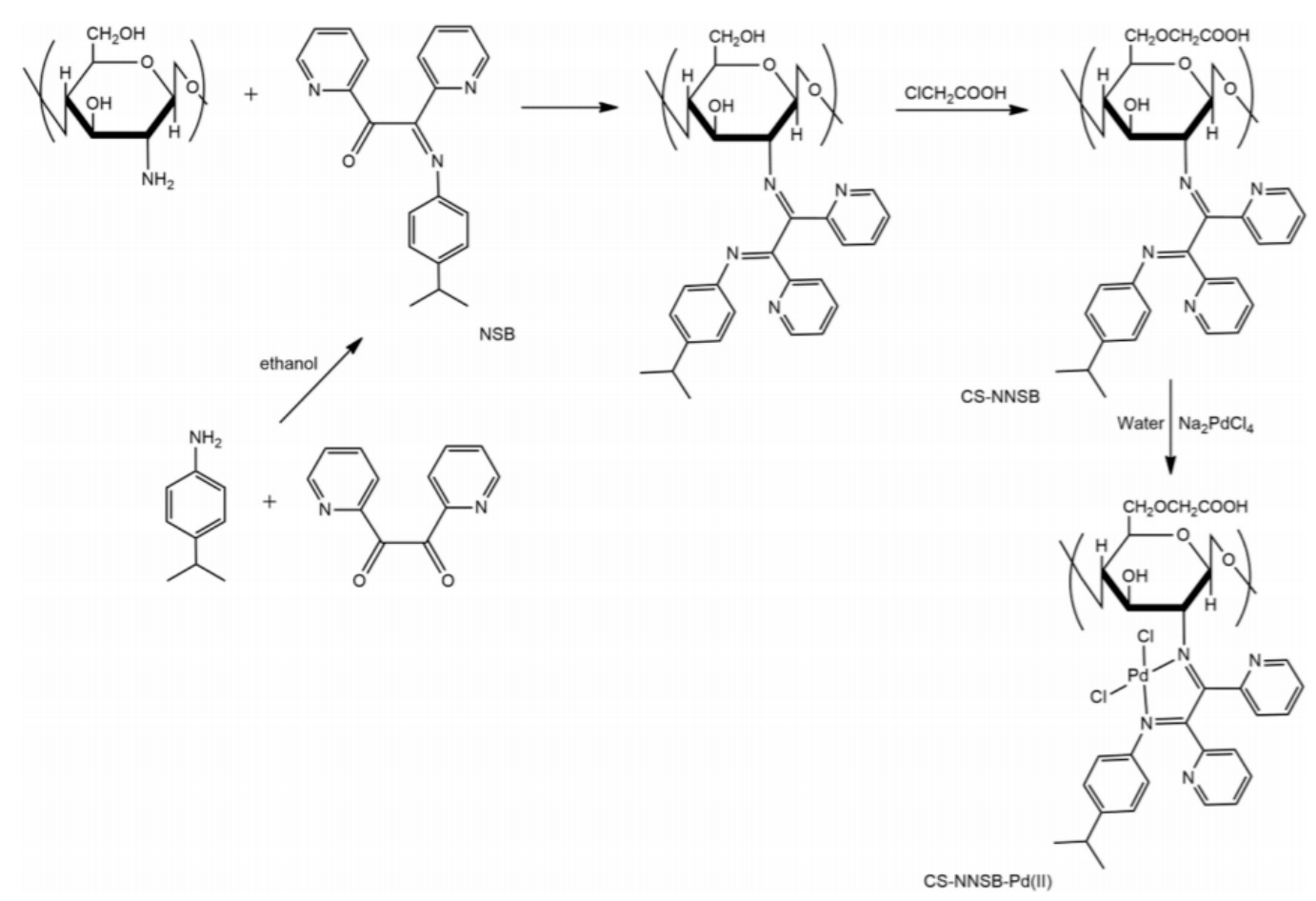

Figure 6. CS-NNSB-Pd(II) catalyst design. Adapted from ref. [102] with permission from Elsevier.

FTIR analysis again confirmed synthesis of the immobilized ligand, and EDAX and XRD showed the coordination of the palladium [102]. The reaction of phenylboronic acid with various halobenzenes-13 compounds-under microwave irradiation and without solvent, resulted in yields from 25 to $97 \%$. The catalyst was recycled six times in the reaction with 4-bromoanisole, and the yields decreased from $97 \%$ in the first run to $73 \%$ in the seventh run.

For support, Baran also used polysaccharides other than chitosan, wherein the immobilization occurred via the hydroxyl on the polymer backbone. The use of other polysaccharides thus required that an amine group, which could react with an aldehyde to yield the Schiff base, first be anchored on the polysaccharide.

In the first system, a starch Schiff-base-supported palladium catalyst was prepared in three steps by using 3-aminopropyl triethoxysilane and 2-thiophenecarboxaldehyde to anchor $\mathrm{Na}_{2} \mathrm{PdCl}_{4}$ [103] (Figure 7). 


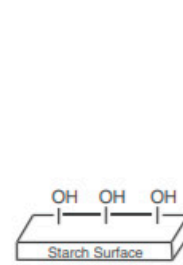

ST

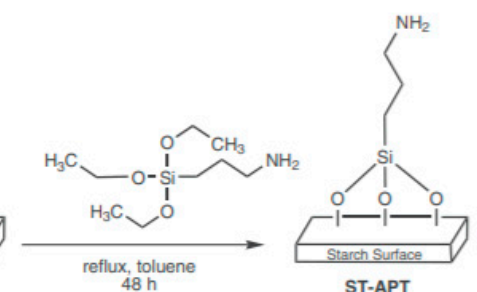

ST-APT

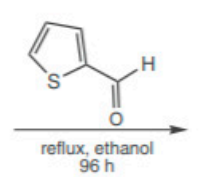

Figure 7. Starch Schiff-base-supported palladium catalyst preparation. Adapted from ref. [104] with permission from John Wiley Sons.

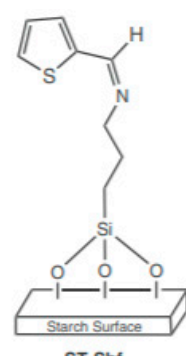

ST-Shf
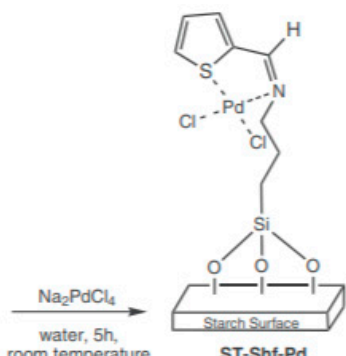

ST-Shf-Pd

The new heterogeneous system was tested under microwave irradiation and solvent-free conditions in the Suzuki reaction with different aryl iodides, bromides, and chlorides with phenylboronic acid while using different bases and catalyst-loading regimens [103]. Under optimized conditions, the yields were between $38-99 \%$, and the catalyst was recycled 10 times with very low palladium ion leaching ( 1\%), a finding that is consistent with the reduction in biphenyl yield from $99 \%$ to $80 \%$ after the 10 cycles.

Baran et al. also used the same procedure with agar [81] and guar gum [104], for which they obtained agar/guar gum-Schiff-base-supported palladium catalysts in three steps. The new catalysts were successfully used in 23 different reactions under microwave irradiation, and the yields obtained ranged from $53 \%$ to $99 \%$ with agar, i.e., AG-Pd [81], and from 33\% to $98 \%$ with guar gum, GG-Pd [104]. The catalyst was reused in 10 successive runs, and negligible leaching of palladium ions from the AG-Pd catalyst was observed.

A cellulose-Schiff-base-supported palladium catalyst was also synthesized by using a similar procedure (Figure 8) [105]. First, cellulose was mixed with 3-Aminopropyltriethoxysilane under reflux in toluene, followed by the Schiff-base modification of cellulose with glyoxal in ethanol. The $\mathrm{Na}_{2} \mathrm{PdCl}_{4}$ solution in water was then dropped into the reaction mixture, which was stirred, filtered, washed with hot water, and dried to yield the CL-Gly-Pd catalyst.

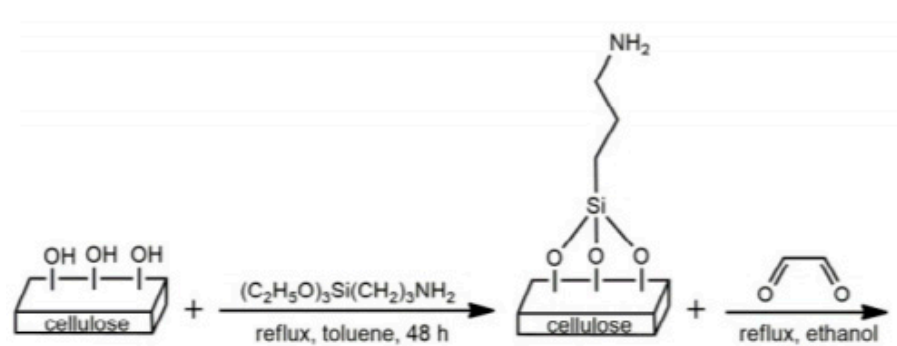

$72 \mathrm{~h}$
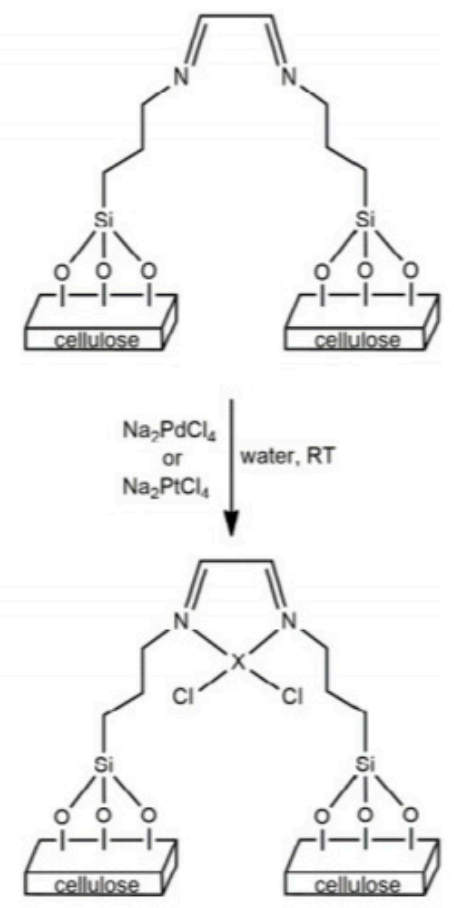

$\mathbf{X}$ : Pd. Pt

Figure 8. CL-Gly-Pd catalyst preparation. Adapted from ref. [105] with permission from Elsevier. 
The Suzuki reaction with the CL-Gly-Pd catalyst was also tested with 22 different substrates, including chloro-, bromo- and iodobenzenes, under solvent-free media and microwave irradiation conditions. The yield varied from $40 \%$ to $98 \%$ in accordance with the substrate [105]. The catalyst in the reaction of 4-iodoanisole with phenylboronic acid was recycled seven times after simple filtration, and the catalysts were regenerated by washing with hot water and ethanol. The catalysts obtained via the regeneration process did not undergo any significant changes relative to the fresh catalyst. Over the course of six cycles, the conversion rate decreased from $98 \%$ to $61 \%$, and leaching tests showed that $2.1 \%$ of the palladium was lost from the catalysts.

Based on the same method, another cellulose-Schiff-base-supported Pd(II) catalyst was prepared in three steps (Figure 9) [106]. First, $\mathrm{NH}_{2}$ functionalized cellulose was prepared by refluxing cellulose and 3-aminopropyltriethoxysilane in dry toluene to yield $\mathrm{NH}_{2}$ modified cellulose $\left(\mathrm{CL}-\mathrm{NH}_{2}\right)$ that was filtered, rinsed with ethanol, and dried. In the second step, $\mathrm{CL}-\mathrm{NH}_{2}$ and 2-pyridinecarboxaldehyde were refluxed in ethanol to form a Schiff base $(\mathrm{CL}-\mathrm{Sc})$, and the product was filtered out, and washed with hot ethanol. Finally, a cellulose-Schiff-base-supported catalyst (CL-Sc-Pd) was synthesized by stirring CL-Sc and $\mathrm{Na}_{2} \mathrm{PdCl}_{4}$ in water, and once the reaction had completed, the palladium catalyst was filtered, rinsed several times with water, and dried.

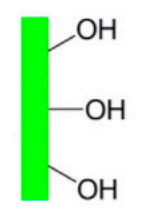

CL

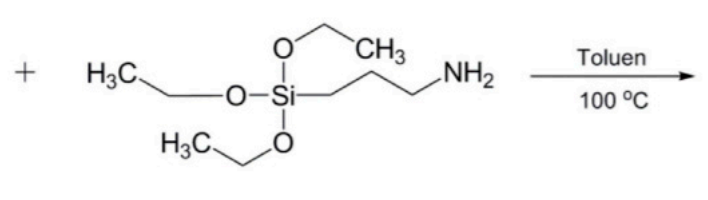

APTES

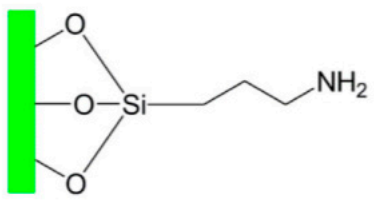

CL-NH ${ }_{2}$<smiles>O=Cc1ccccn1</smiles>

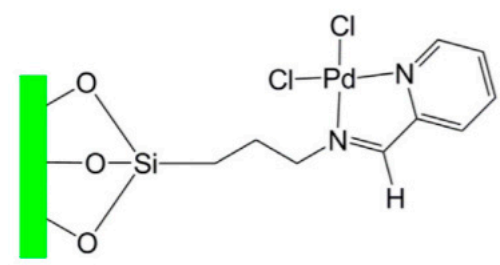

CL-Sc-Pd

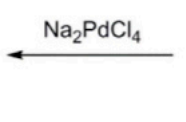

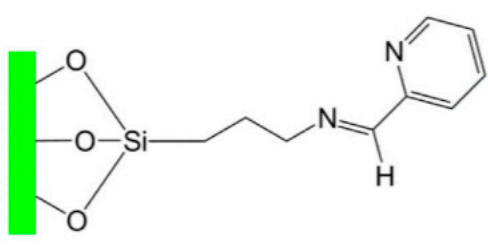

CL-Sc

Figure 9. Cellulose-supported Pd(II) catalyst. Adapted from ref. [107] with permission from Elsevier.

FTIR spectra of the new catalysts indicated that the Schiff-base reaction of the CL- $\mathrm{NH}_{2}$ with 2-pyridinecarboxaldehyde was successful and that the palladium ion was coordinated to the support via the imine [106]. In addition, TG/DTG analysis of the new system confirmed that it is thermal durable.

The heterogeneous system was tested in the Suzuki cross-coupling of 20 substrates, including chloro-, bromo- and iodobenzenes, under solvent-free media and microwave irradiation conditions, and the yields obtained ranged from $5 \%$ to $99 \%$ while the TOFs were up to $200,000 \mathrm{~h}^{-1}$. After the reaction of 4-bromoanisole with phenylboronic acid, the catalyst was easily recovered by simple filtration, washed with hot methanol and water, and reused for an additional seven runs. Catalyst activity decreased slightly in each recycle from $99 \%$ in the first run to $71 \%$ in the eighth run, which indicates that palladium leached from the cellulose support.

Likewise, Baran et al. [107] also prepared a starch-supported palladium catalyst in three steps (Figure 10), wherein the $\mathrm{NH}_{2}$ functionalized starch $\left(\mathrm{ST}-\mathrm{NH}_{2}\right)$ was reacted with 2,4-dihydroxybenzaldehyde to form a Schiff base (ST-Sc) followed by stirring with $\mathrm{Na}_{2} \mathrm{PdCl}_{4}$ in water to yield the starch-supported $\mathrm{Pd}(\mathrm{II})$ catalyst. 


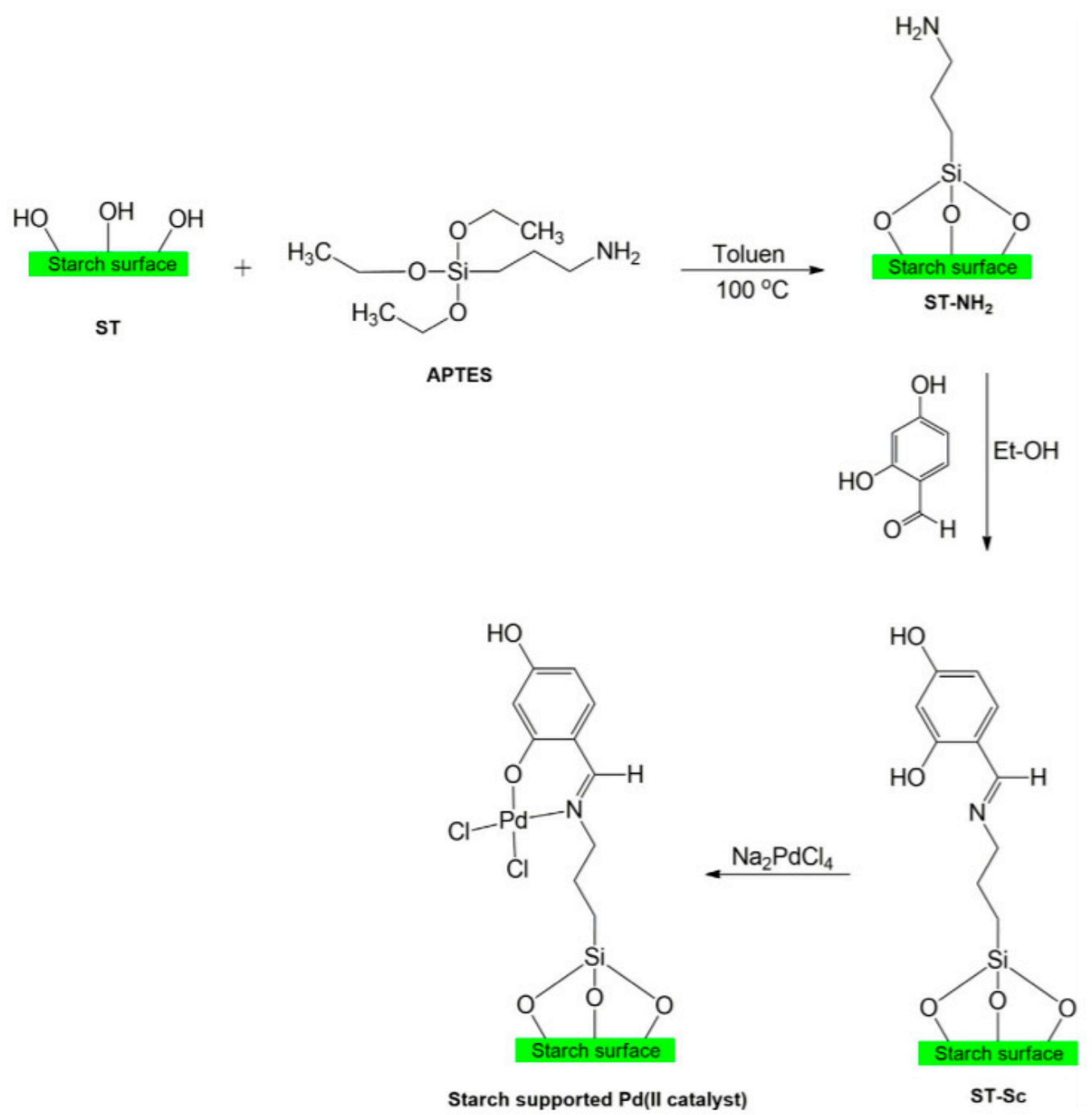

Figure 10. Starch-supported $\mathrm{Pd}(\mathrm{II})$ catalyst. Adapted from ref. [107] with permission from Elsevier.

FTIR spectra of the new catalysts again indicated the formation of a Schiff base that was used to coordinate the palladium ions [107], and TG/DTG analysis of the new system confirmed that it is thermal durable. Finally, the new heterogeneous system was tested in the Suzuki cross-coupling of 23 different substrates under solvent-free media and microwave irradiation conditions. High yields of $30 \%$ to $100 \%$ and TOF up to $300 \mathrm{~h}^{-1}$ were obtained. The catalyst was easily recovered by simple filtration and washing with hot methanol and water after the reaction of 4-bromoanisole with phenylboronic acid, and reused for an additional nine runs. Catalyst activity decreased slightly, from $100 \%$ to $61 \%$, each time it was recycled, and after the tenth cycles of catalyst reuse, $3.5 \%$ of the palladium was found to have leached from the starch support.

Lastly, Baran prepared another Schiff-base-supported $\mathrm{Pd}(\mathrm{II})$ catalyst by using pectin (Figure 11) [108]. As before, the reaction was performed under solvent-free and microwave conditions, and it resulted in high yields of $41 \%$ to $99 \%$. Moreover, in recycling tests, the Pct-Pd catalyst exhibited superior performance as it continued to produce high yields of $91 \%$ even after 12 runs, during which only negligible metal leaching was observed. 


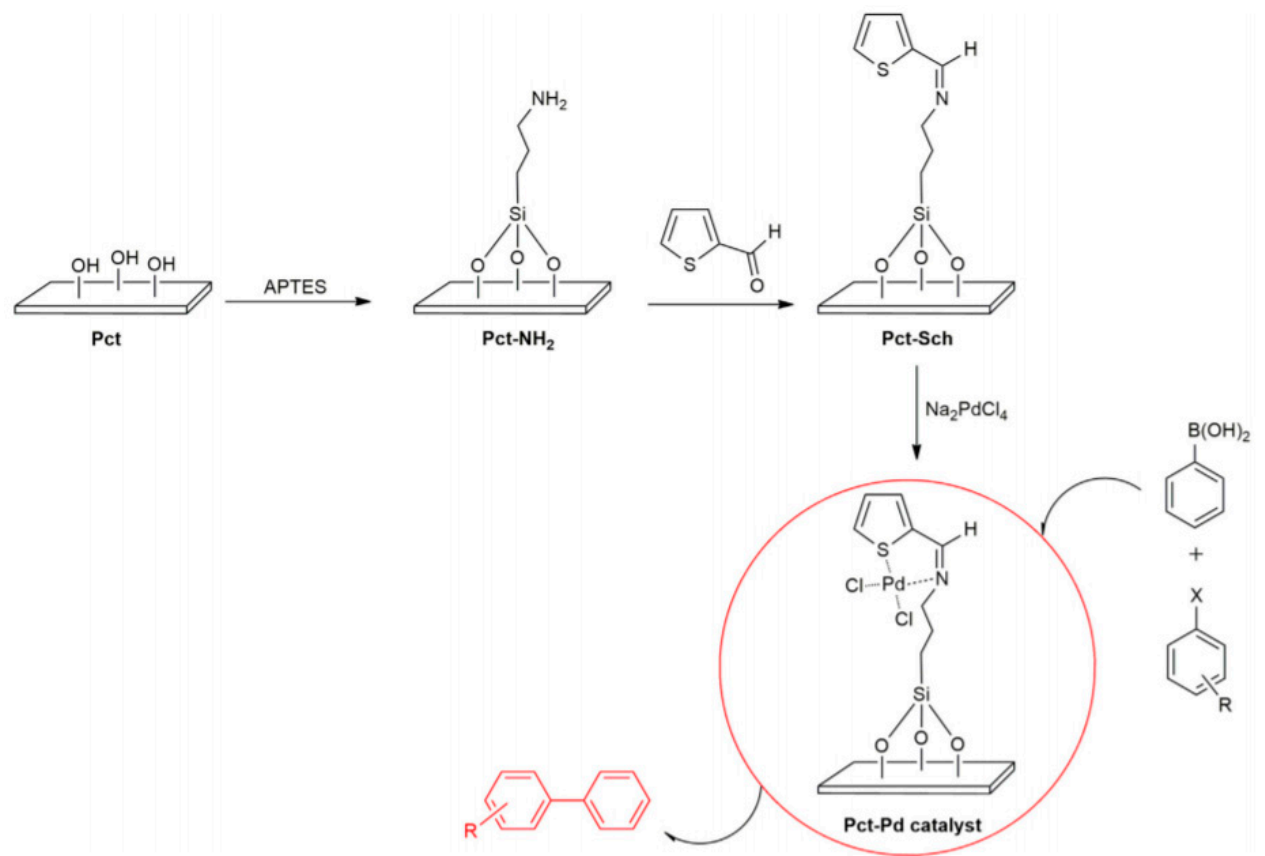

Figure 11. Pct-Pd catalyst fabrication. Adapted from ref. [108] with permission from Elsevier.

Dong et al. [109] reported on the synthesis of new heterogeneous palladium catalyst in three steps: (1) cellulose was reacted with 3-aminopropyltriethoxysilane to yield Cell- $\mathrm{NH}_{2}$; (2) synthesis of Schiff-base functionalized cellulose; (3) addition of $\mathrm{Na}_{2} \mathrm{PdCl}_{4}$ to yield the final catalyst [109]. Both ${ }^{13} \mathrm{C}-\mathrm{NMR}$ and FTIR analyses corroborate that cellulose has successfully been modified for the metal-ligand interaction. The thermal stability of the catalyst showed that the decomposition temperature of the new composite is around $290^{\circ} \mathrm{C}$, and a TEM image of the fresh catalyst proved that no $\operatorname{Pd}(0)$ particles were left over on the cellulose surface, which is in agreement with the XPS data of the $\mathrm{Pd}(\mathrm{II})$ oxidation state in the catalyst.

The performance of the catalyst in Suzuki cross-coupling, using chlorobenzene, idobenzene and different bromobenzenes with phenylboronic acid derivatives in $\mathrm{EtOH} / \mathrm{H}_{2} \mathrm{O}(1: 1)$ at $70{ }^{\circ} \mathrm{C}$, yielded TOFs from 53 to $341 \mathrm{~h}^{-1}$ [109]. The catalyst was also tested for reusability for five runs, during which the yield of 4-methoxybiphenyl decreased from $96 \%$ to $77 \%$.

Sabaqian et al. proposed a different approach, in which the catalysts could be separated at the end of the reaction by magnetic force (Figure 12). Thus, a magnetically retrievable catalytic system involving $\mathrm{Pd}(\mathrm{II})$ acetate supported on an amidoxime-functionalized cellulose nano-magnetic catalyst (nano- $\mathrm{Fe}_{3} \mathrm{O}_{4} @ \mathrm{AOFC} / \mathrm{Pd}(\mathrm{II})$ ) was prepared [110]. The catalyst was prepared in four stages (Figure 12): (1) 2-chloroacetonitrile in isopropanol was added by drops to an aqueous solution of cellulose with $\mathrm{NaOH}$ and stirred to form cyanomethyl cellulose that was separated by filtration, rinsed three times with 70\% ethanol, and dehydrated with absolute alcohol; (2) conversion of the nitrile group to an amidoxime group, yielding amidoxime functionalized cellulose (AOFC), by addition of hydroxylamine hydrochloride $\left(\mathrm{NH}_{2} \mathrm{OH}\right.$. $\left.\mathrm{HCl}\right)$ in EtOH/ $\mathrm{H}_{2} \mathrm{O}(5: 1 v / v)$ to cyanomethyl cellulose solution in DMF; after stirring, the amidoxime functionalized cellulose was filtrated off, washed thoroughly several times with distilled water and ethanol and dried, yielding synthetized amidoxime functionalized cellulose; (3) AOFC was mixed with palladium acetate in acetonitrile, after which the resulting brown solid was filtered, washed with acetone and THF and dried to give AOFC/Pd(II). The Pd(II) content as obtained by ICP was $0.104 \mathrm{mmol} \cdot \mathrm{g}^{-1}$; (4) an aqueous suspension of $\mathrm{AOFC} / \mathrm{Pd}(\mathrm{II})$ was added to an aqueous suspension of magnetic nanoparticles, which were obtained by alkaline hydrolysis of iron(II) chloride and iron(III) chloride (molar ratio of 1:2) in aqueous solution, heated at $70^{\circ} \mathrm{C}$ and magnetically stirred. Then it was filtered magnetically and the obtained solid, nano-Fe $\mathrm{O}_{4} @ \mathrm{AOFC} / \mathrm{Pd}(\mathrm{II})$ was washed with water and dried under vacuum. 

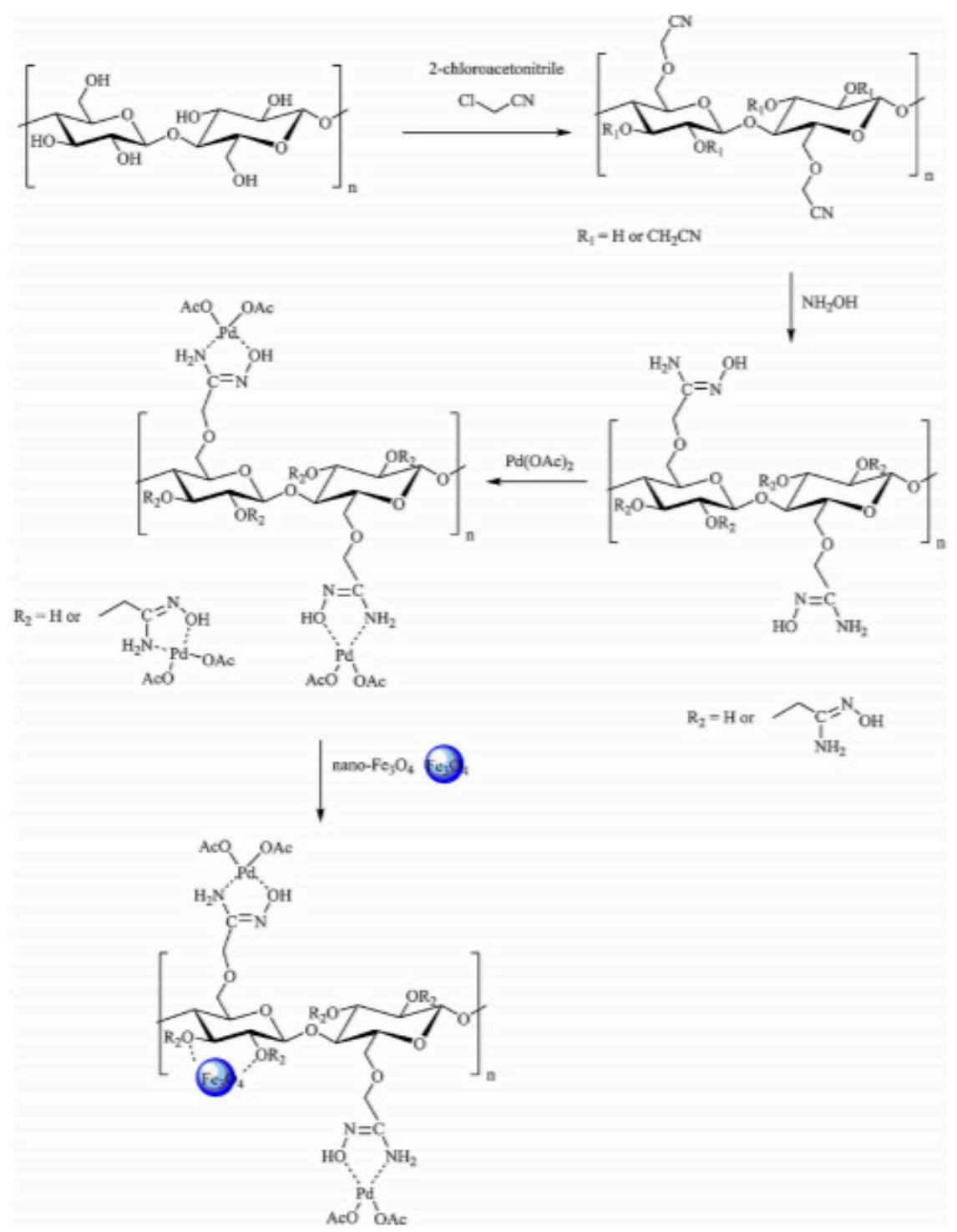

Figure 12. Nano- $\mathrm{Fe}_{3} \mathrm{O}_{4} @ \mathrm{AOFC} / \mathrm{Pd}(\mathrm{II})$ synthesis. Adapted from ref. [110] with permission from Elsevier.

FTIR spectra confirmed the conversion of the cyano groups to amidoxime groups, the presence of $\mathrm{Pd}(\mathrm{OAc})_{2}$, and the presence of $\mathrm{Fe}-\mathrm{O}$ in $\mathrm{Fe}_{3} \mathrm{O}_{4} @$ cell-Amidoxime- $\mathrm{Pd}(\mathrm{OAc})_{2}$ [110]. The XRD diffraction peaks indicated that $\mathrm{Fe}_{3} \mathrm{O}_{4}$ magnetic nanoparticles were present mainly in the cubic structure, and the HRTEM images of the $\mathrm{Fe}_{3} \mathrm{O}_{4} @$ cell-Amidoxime-Pd(OAc) $)_{2}$ nanocomposite indicate that it is nearly in composite structures. In addition, the magnetization study indicates that the samples are superparamagnetic at room temperature, and thus, they could be easily recovered by applying an external magnetic field.

The cross-coupling reactions between different halobenzenes and phenylboronic acid in an ethanol: $\mathrm{H}_{2} \mathrm{O}$ (2:1) mixture showed high reaction yields that ranged from 50 to $95 \%$. The new catalyst was also successfully recycled by using a magnet, then washed with water and hot ethanol to remove adsorbed organic substrates and salt, and reused. Five runs were thus performed in the reaction of iodobenzene and phenylboronic acid. For the second and third runs, only a minor loss of catalytic activity was observed, but the yield decreased to $88 \%$ and $85 \%$ during the fourth and fifth runs, respectively, probably due to the gradual loss of the catalyst during washing. 


\subsection{Immobilization of Palladium Via other Methods}

Lasri et al. [111] also used chitosan as support, in this case using the amine group on the polymer as the anchoring point via coordination to the palladium. Their approach, however, involved first the much more complicated synthesis of palladium oxadiazoline (1) from which they derived ketoimine (2) complexes (Figure 13).

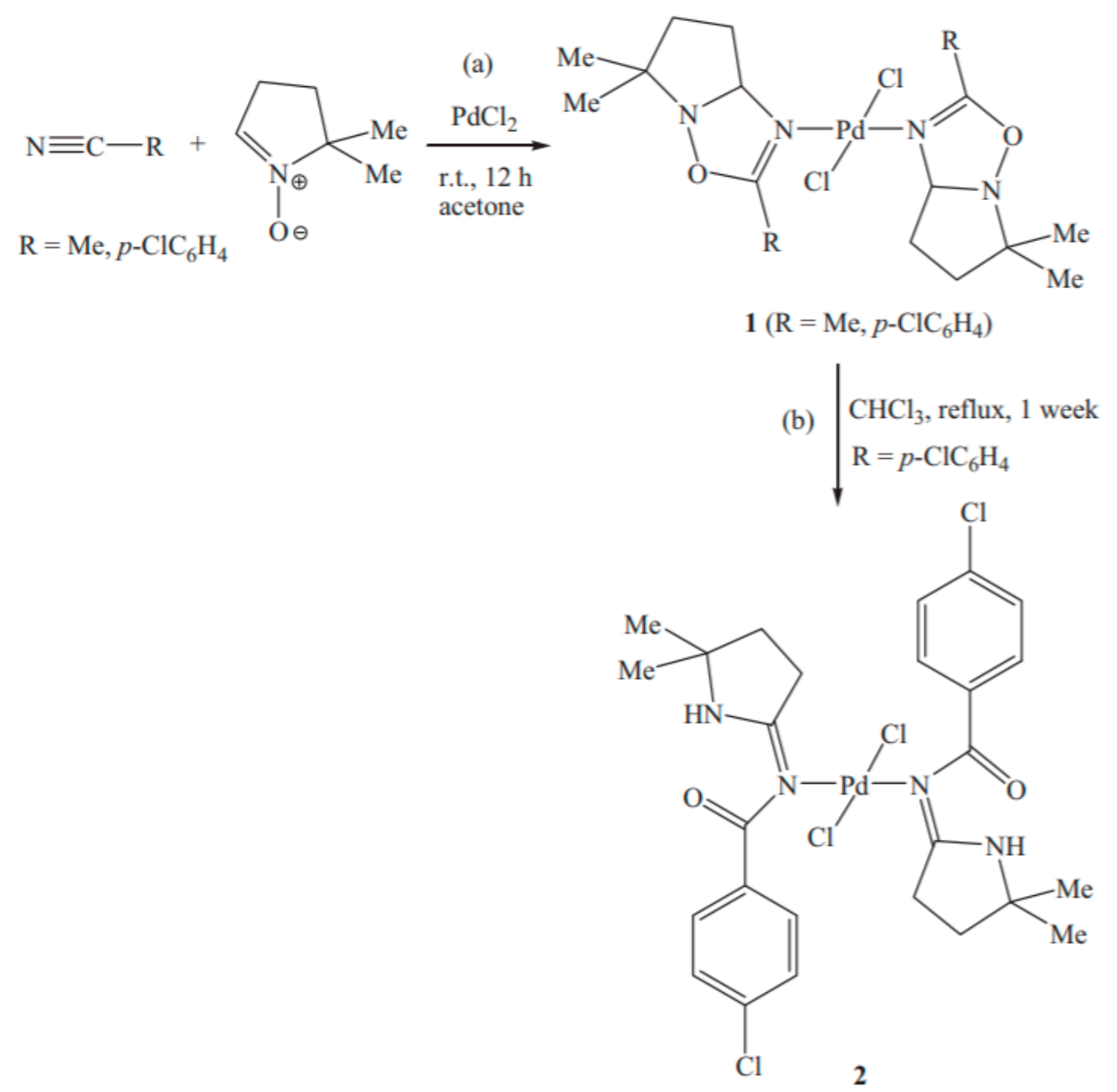

Figure 13. Synthesis of ketoimine palladium(II) complexes. Adapted from ref. [111] with permission from Elsevier.

The supported catalyst was prepared as follows (Figure 14) [111]: water was added to a mixture of chitosan to form a colloidal dispersion, and each palladium complex, which was dissolved in chloroform, was slowly added to the reaction system. A NaOH solution was then slowly added until the colloidal dispersion became neutral, and after stirring, the reaction was stopped and the reaction mixture was filtered. The viscous solution that was obtained was allowed to stand for $96 \mathrm{~h}$ at room temperature to yield a mechanically stable membrane that was washed several times with solvents in the following order: chloroform, acetonitrile, and methanol.

The palladium loading as measured by inductively coupled plasma-atomic emission spectrometry (ICP-AES) was $0.16 \%(\mathrm{wt} / \mathrm{wt})$ palladium on the chitosan membrane (Pd-chit 1 or Pd-chit 2), corresponding to a catalyst loading of $1.5 \times 10^{-2} \mathrm{mmol}$ palladium complex per gram of biopolymer [111].

Both heterogeneous catalysts were tested in the reaction of 4-bromoanisole and phenylboronic acid under various conditions and with different additives, resulting in yields up to $100 \%$. Similar yields were demonstrated with 4-iodoanisole and even 4-chloroanisole. Catalyst recycling was also 
investigated after the catalyst was removed from the reaction mixture by filtration, washed with dichloromethane and water, dried at room temperature, and then reused for a second run. This regeneration process was repeated seven times, over the course of which a gradual loss in yield from $83 \%$ to $7 \%$ was observed. As ICP-AES analysis confirmed negligible palladium leaching from the supported systems, it was suggested that the decrease in catalytic activity could be attributed to the aggregation of palladium to nanoparticles or the blockage of the active sites.

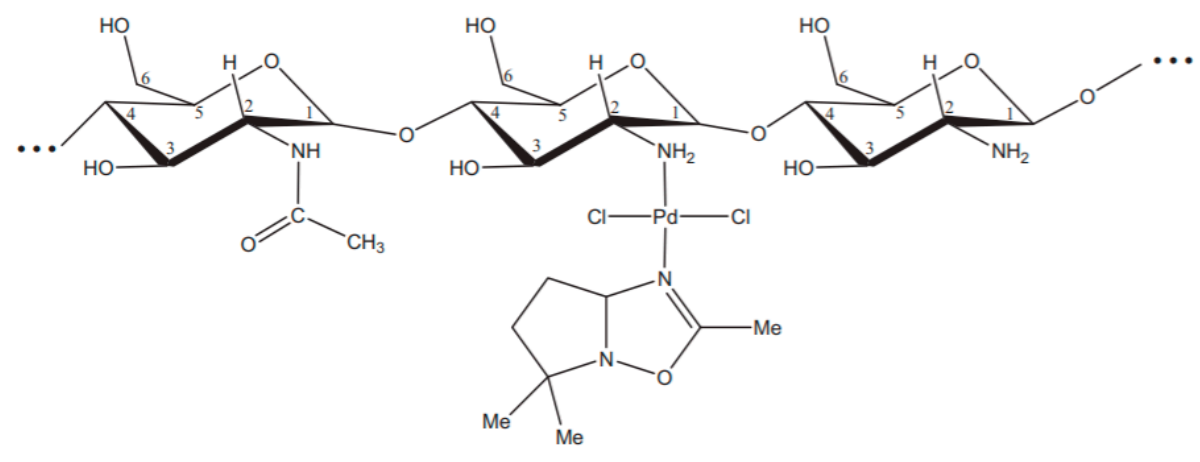

Pd-Chit 1

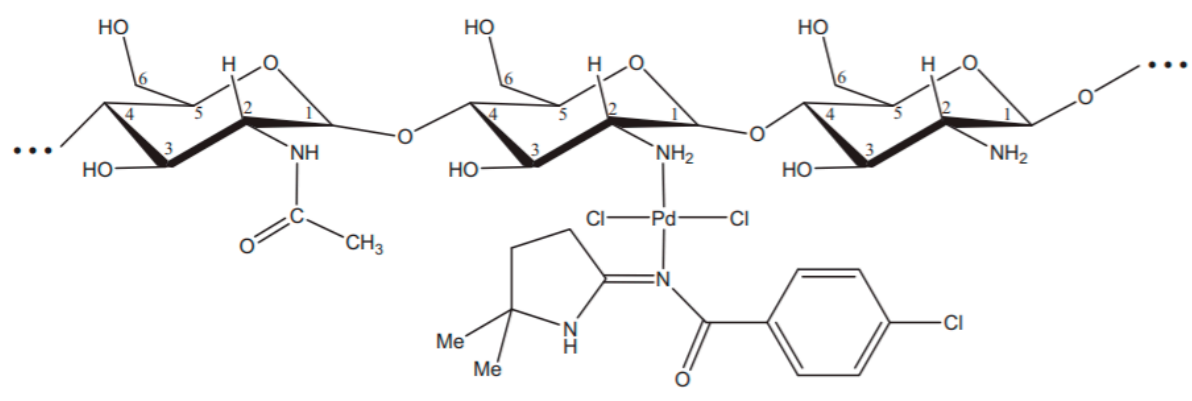

Pd-Chit 2

Figure 14. Supported chitosan-Pd(0) catalyst. Adapted from ref. [111] with permission from Elsevier.

Another polysaccharide that is commonly used in the immobilization of metal catalysts, including palladium, is cellulose. In this case, the hydroxyl groups on the polymer are the anchoring points. Wang et al. [112] reported on the multistep synthesis of a cellulose-supported $N$-methylimidazole-palladium catalyst (Cell-NHC-Pd). First, cellulose $p$-toluenesulfonate (Cell-OTs) was prepared by mixing cellulose in $\mathrm{N}, \mathrm{N}$-dimethylacetamide, after which the solvent was partially distilled in a nitrogen atmosphere and anhydrous $\mathrm{LiCl}$ was added to the suspension, which was then cooled until the cellulose was fully dissolved. Then a mixture of triethyl amine and $N, N$-dimethylacetamide was added under stirring, and after cooling and stirring, a solution of $p$-toluenesulfonyl chloride in $N, N$-dimethylacetamide was added dropwise. The homogeneous reaction mixture was stirred and then slowly poured into ice water to yield precipitate that was filtered off, washed with distilled water and ethanol, suspended in acetone, and reprecipitated into distilled water. Finally, after filtration and washing with ethanol, the sample was dried under vacuum. In the next stage, Cell-OTs was added to DMSO, and the mixture was stirred to completely dissolve the Cell-OTs (Figure 15). $\mathrm{N}$-methylimidazole was then added to the reaction mixture under nitrogen, and the viscous black mixture obtained was stirred. After cooling, it was added dropwise into acetone and stirred vigorously, and the resulting [Cell-NHC][OTs] ${ }^{-}$was obtained. The [Cell-NHC][OTs] $]^{-}$was then dissolved in a solution of $\mathrm{NaCl}$ in acetone to replace the $\mathrm{OTs}^{-}$with $\mathrm{Cl}^{-}$. The precipitate (Cell-NHC-Cl) was collected via filtration, and the powder was vacuum dried. Finally, the Cell-NHC-Pd complex was prepared under nitrogen by adding Cell-NHC-Cl to a solution of $\mathrm{Pd}(\mathrm{OAc})_{2}$ in $\mathrm{DMF}$ and mixing. After cooling to room temperature, the reaction mixture was filtered, and the solid black product obtained was washed once each with distilled water, absolute ether, and 
absolute ethyl alcohol successively, and then dried under reduced pressure at room temperature to give the dark palladium complex (Cell-NHC-Pd).

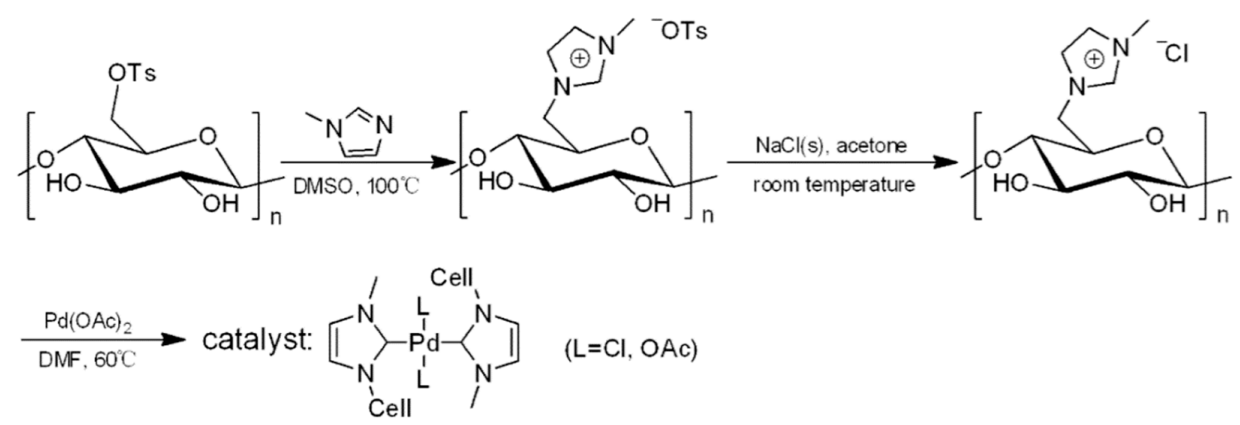

Figure 15. Schematic of Cell-NHC-Pd formation. Adapted from ref. [112] with permission from Elsevier.

FTIR analysis of the catalyst suggested that the NHC-Pd complex was formed [112], and thermogravimetric analysis (TGA) demonstrated that cellulose was markedly stable in an oxygen-containing atmosphere. In addition, XPS spectroscopy revealed that the catalyst contained both $\mathrm{Pd}(0)$ and $\mathrm{Pd}(\mathrm{II})$, as the $\mathrm{Pd}(\mathrm{II})$ species were likely partially reduced in the presence of the cellulose backbone.

The heterogeneous Suzuki cross-coupling reaction was performed in DMF: $\mathrm{H}_{2} \mathrm{O}$ (1:1) with different halobenzenes and with various phenylboronic acids. Yields ranged from $10 \%$ in the case of chlorobenzenes to $97 \%$ with bromo- and iodobenzenes. Catalyst recycling was studied with 4-bromoanisole and phenylboronic acid, repeated five times, and over the course of those runs, the yield decreased from $91 \%$ to $58 \%$. In addition, ICP-AES detected palladium leaching of $1.2 \%$ after the fifth cycle. Therefore, it was concluded that the decrease of activity may be due to the aggregation of palladium as nanoparticles during the reaction, which was supported by TEM images.

Chen et al. [113] reported on the immobilization of $\mathrm{Pd}(\mathrm{OAc})_{2}$ on Xylan-type hemicelluloses by attaching $4^{\prime}$-(4-bromobenzyl) $2,2^{\prime}: 6^{\prime}, 2^{\prime \prime}$-terpyridine, which served as the ligand, to the polymer in two steps (Figure 16).

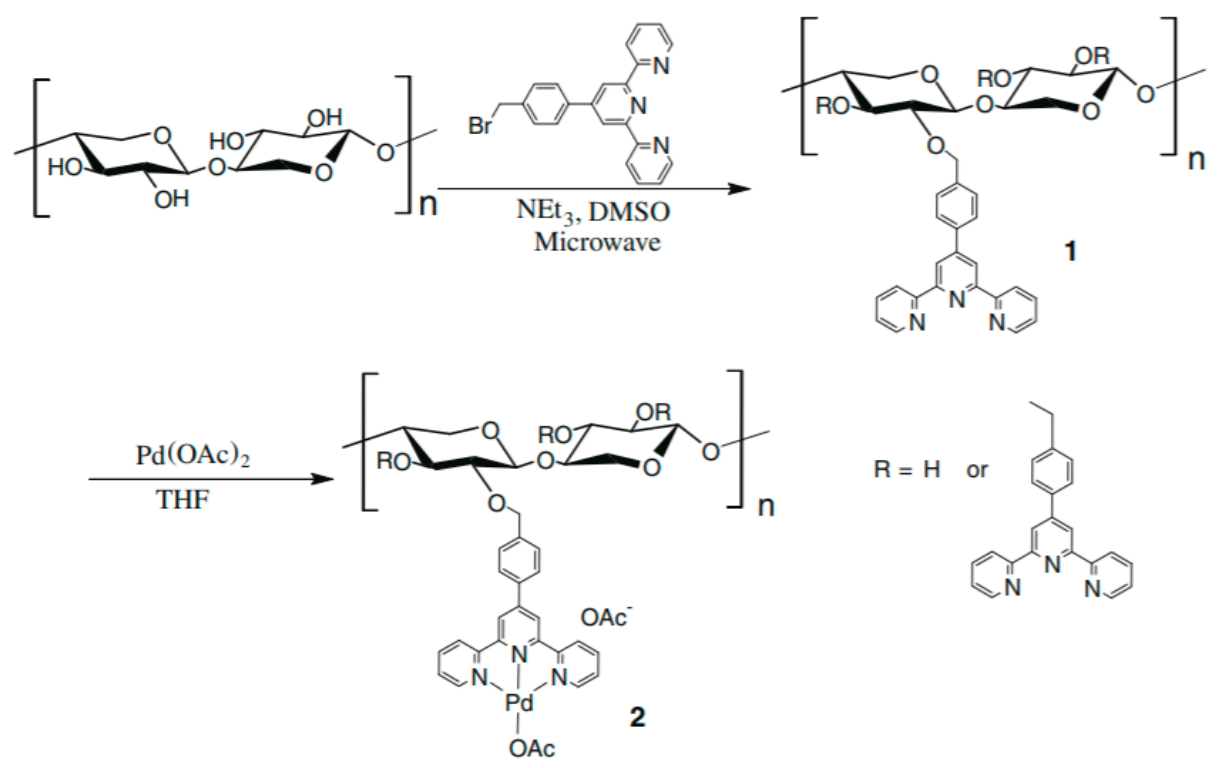

Figure 16. Preparation of palladium-based xylan-type hemicellulose catalyst. Adapted from ref. [113] with permission from Royal Society of Chemistry.

X-ray photoelectron spectroscopy (XPS) analysis indicated that the oxidation state of palladium in the freshly prepared catalyst was $\mathrm{Pd}(\mathrm{II})$, whereas the TEM images of the fresh prepared xylan-type 
hemicelluloses- $N-P d$ was granular, and the nanoparticles had diameters of about $10 \mathrm{~nm}$ [113]. The catalyst was tested with different solvents and bases, and it was found that under the tested conditions, $\mathrm{K}_{2} \mathrm{CO}_{3}$ was the best base and methanol the preferred solvent. The catalyst was also successfully employed with a large range of phenylboronic acids and aryl halides, yielding conversions from $78 \%$ to $98 \%$. It was also successfully recycled five times by using 4-bromoanisole and phenylboronic acid. In each cycle, a slight loss of activity was observed from a $94 \%$ conversion rate obtained in the first run to $86 \%$ in the sixth run.

Wang et al. [114] reported on the heterogenization of $\mathrm{Pd}(\mathrm{OAc})_{2}$ on cellulose by immobilization of triphenylphosphine, which served as the ligand, to the polymer in three steps (Figure 17).

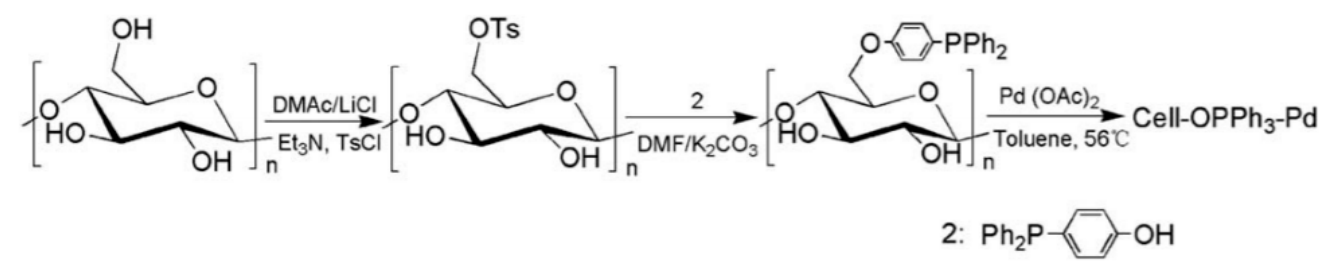

Figure 17. Synthetic pathway of Cell-OPPh3 and Cell-OPPh3-Pd. Adapted from ref. [114] with permission from Wiley \& Sons.

FTIR spectra of the new catalyst indicated that a new $\mathrm{C}-\mathrm{O}$ bond of Cell-OPPh 3 was synthesized. The success of grafting triphenylphosphine onto the cellulose backbone was also confirmed by CP/MAS ${ }^{13} \mathrm{C}-\mathrm{NMR}$ and ${ }^{31} \mathrm{P}-\mathrm{NMR}$ spectroscopy. Furthermore, thermogravimetric analysis evaluated the stability of the cellulose-supported catalyst in air and high temperature [114].

The yields of the catalyst products obtained in Suzuki cross-coupling, using different halobenzenes with phenylboronic acid derivatives in ethanol at $80^{\circ} \mathrm{C}$, ranged from $4 \%$ to $98 \%$ [114]. The reusability of the catalyst in the Suzuki-Miyaura coupling reaction of 4-bromoanisole with phenylboronic acid was also tested for four runs. The catalytic activity significantly decreased after the third cycle (after the third usage the yield decreased to $65 \%$ from the $95 \%$ obtained after the first usage).

The research group of Wolfson and Levy-Ontman reported on the synthesis of palladium-based catalysts within renewable polysaccharide supports by using different anchoring [115-117]. The catalysts were prepared in two steps: (1) add an aqueous solution of $\operatorname{Pd}(\mathrm{OAc})_{2}(\mathrm{TPPTS})_{2}$ or $\mathrm{PdCl}_{2}$ (TPPTS) $)_{2}$, which was prepared from the corresponding palladium salt and the ligand (TPPTS = sodium triphenylphosphine trisulfonate ligand), to an aqueous solution of the polymer. The mixture was then deep frozen in a tube at $-20^{\circ} \mathrm{C}$ for $24 \mathrm{~h}$ until the liquid was completely frozen and then subjected to lyophilization for $48 \mathrm{~h}$ to yield a dried, "sponge-like" xerogel catalyst.

FTIR analysis demonstrated that the complex was attached to the polysaccharide by a new bond between the sulfonate groups of TPPTS and the hydroxyl groups of the polysaccharide [115], thus preventing the complex from leaching to the solvent and allowing catalyst recycling.

The effect of solvent type on the catalytic performance of the iota carrageenan-based palladium catalyst showed that ethanol was the preferred solvent. Moreover, the effect of polysaccharide type on the reaction performance was also studied, using two-branched polysaccharides, guar gum, and locust bean gum with only hydroxyl groups; carrageenan of the types iota, kappa, and lambda, the backbones of which also have anionic sulfate; red microalgae polysaccharide, which has anionic carboxyl and sulfate groups in its structure; chitosan with amine groups; and xanthan gum, which has hydroxyl, pyruvate, and carboxylate groups in its structure. It was found that although the catalysts supported on guar gum, locust bean gum, and xanthan gum gave the highest conversions, their reaction mixtures exhibited some miscibility, which rendered their separation and recycling difficult. In contrast, the three carrageenan-based catalysts (among which the iota-based catalyst was the most stable) were insoluble in the reaction conditions and could be easily filtrated and recycled.

The Suzuki cross-coupling of several halobenzenes with phenylboronic acids was performed with the iota-based catalyst and yielded conversions from $15 \%$ to $77 \%$ after $24 \mathrm{~h}$, and the catalyst 
iota-Pd(OAc $)_{2}$ (TPPTS $)_{2}$ was successfully recycled four times, over the course of which the conversion decreased from $77 \%$ in the first run to $60 \%$ in the fifth run, and no catalyst leaching was detected [116].

In another catalyst-synthesis method, palladium-based TPPTS complexes were immobilized in hydrogel beads [118]. Bead-preparation performance was tested with two different methods that involved dropping the complex and various polysaccharide solutions into (1) an aqueous or ethanol solution of $0.5 \mathrm{M}$ calcium chloride or (2) an aqueous solution of chitosan. The beads that were formed with iota carrageenan and chitosan yielded the most stable heterogeneous catalyst system. SEM-EDS analysis of the hydrogels showed that the complex was immobilized in the hydrogels and that the beads that were made in chitosan were less condensed than those that were made in the $\mathrm{CaCl}_{2}$ solution . As expected, the palladium did not leach to the reaction mixture when ethanol was used as a solvent. In addition, the catalyst was recycled three times without any loss in activity.

\section{Summary}

Table 3 lists the various palladium-based polysaccharide catalytic systems that were prepared via the immobilization of $\mathrm{Pd}(\mathrm{II})$ species, including the polysaccharide type, the reaction condition and heating technique, and the catalytic performance. As previously stated, a comparison between the systems should take into account the preparation procedure, the reaction procedure, the catalytic performance, and the reuse of the catalyst.

Table 3. Comparison of catalytic performances of representative palladium catalysts immobilized on renewable polysaccharide in Suzuki-Miyaura cross-coupling of halobenzenes and phenylboronic acid.

\begin{tabular}{|c|c|c|c|c|c|c|}
\hline Ref & Polymer & Halobenzene & Solvent & $\mathrm{T}\left({ }^{\circ} \mathrm{C}\right)$ & Heating & TOF $\left(h^{-1}\right)$ \\
\hline [98] & Chitosan & 4-Bromophenol & Water & 130 & MW & 10 \\
\hline [100] & Chitosan-Ulva & 4-Bromoanisole & No & 50 & MW & 75,000 \\
\hline [101] & Chitosan & 4-Bromoanisole & No & 120 & MW & 240,964 \\
\hline [102] & Chitosan & 4-Bromoanisole & None & 120 & MW & 202,087 \\
\hline [81] & Agar & 4-Bromoanisole & No & 50 & MW & 3233 \\
\hline [104] & Guar Gum & 4-Bromoanisole & No & 50 & MW & 60,000 \\
\hline [105] & Cellulose & 4-Bromoanisole & No & 50 & MW & 4028 \\
\hline [106] & Cellulose & 4-Bromoanisole & No & 50 & MW & 198,000 \\
\hline [107] & Starch & 4-Bromoanisole & No & 50 & MW & 312,500 \\
\hline [112] & Cellulose & 4-Bromoanisole & DMF: $\mathrm{H}_{2} \mathrm{O}(1: 1)$ & 80 & $\mathrm{CV}$ & 61 \\
\hline [113] & $\begin{array}{c}\text { Xylan-type } \\
\text { hemi-cellulose }\end{array}$ & 4-Bromoanisole & Methanol & 25 & $\mathrm{CV}$ & 9.4 \\
\hline [114] & Cellulose & 4-Bromoanisole & $\mathrm{EtOH}$ & 80 & $\mathrm{CV}$ & 341 \\
\hline [115] & Iota carrageenan & Iodobenzene & $\mathrm{EtOH}$ & 50 & $\mathrm{CV}$ & 1.3 \\
\hline [118] & Iota carrageenan & Iodobenzene & $\mathrm{EtOH}$ & 50 & $\mathrm{CV}$ & 1.71 \\
\hline
\end{tabular}

Regarding catalyst preparation procedures, in all of the systems except those that were reported by Wolfson and Levy-Ontman, the immobilization proceeded via a Schiff base that was anchored to the polysaccharide backbone directly or by another organic molecule. Table 3 also shows that chitosan was used often as the polysaccharide, mainly because the Schiff base, which functioned as a ligand to the palladium salt, could be easily synthesized by reacting a corresponding aldehyde with the amine group on the chitosan backbone. When using other polysaccharides, such as cellulose, agar or pectin, a preliminary step is required to anchor an amine group to the polymer.

The synthesis of the Schiff bases was tedious, and it required multistep procedures that usually took several hours to days to complete and that involved large amounts of organic solvents for both the reactions and the washing steps. In addition, the yields of the various steps were not 
always high, and thus, some of the reagents were washed away. In contrast, in the case where the catalyst was immobilized by TPPTS [105-108], the preparation procedure, which only used water, was relatively simple.

Without a doubt, using MW instead of CV, and preferably without a solvent, not only made the system much more environmentally friendly, but also resulted in a manyfold acceleration of the reaction. As such, the various catalysts that were synthesized by Baran and coworkers yielded enormous TOFs, up to $300,000 \mathrm{~h}^{-1}$ [107].

In all the systems, the catalysts were stable and could be recycled by simple separation by filtration, even for 10 successive uses. In addition, in all the cases except for the system of Levy-Ontman et al. [115], the catalyst was washed and dried before each reuse, which ultimately required the use of more organic solvents and energy. In addition, while the first two or three cycles typically returned relatively stable yields, subsequent yields gradually decreased in all systems except that with the pectin [108]. As negligible or very minimal leaching of palladium was detected in all systems, the reduction in the yield was attributed either to a loss of catalyst in each filtration step or to partial reduction of the palladium under reaction conditions, which led to its aggregation.

Many polysaccharides can be used as supports for the heterogenization of palladium complexes by using various methods. In general, the preparation of immobilized complexes is labor intensive and is associated with the use of large amounts of organic solvents, yet they can also be easily separated and recycled. The different catalysts were successfully used to prepare a variety of biaryls, and as expected, using iodo- or bromobenzenes yielded much higher activity than in the case of chlorobenzene. Finally, microwave irradiation facilitates much more rapid and greener synthesis procedures than conventional heating.

Author Contributions: Writing-Original Draft Preparation and Writing-Review, A.W. and O.L.-O. All authors have read and agreed to the published version of the manuscript.

Funding: This research received no external funding.

Conflicts of Interest: The authors declare no conflicts of interest.

\section{References}

1. Diederich, F.; Stang, P.J. Metal-Catalyzed Cross-Coupling Reactions; John Wiley \& Sons: Weinheim, Germany, 2008.

2. Kohei, T.; Miyaura, N. Introduction to cross-coupling reactions. In Cross-Coupling Reactions, 1st ed.; Miyaura, N., Ed.; Springer: Berlin/Heidelberg, Germany, 2002; pp. 1-9.

3. Miyaura, N. Cross-Coupling Reactions: A Practical Guide in Topics in Current Chemistry; Springer: Berlin/Heidelberg, Germany, 2002; Volume 219.

4. Miyaura, N.; Suzuki, A. Palladium-catalyzed cross-coupling reactions of organoboron compounds. Chem. Rev. 1995, 95, 2457-2483. [CrossRef]

5. Littke, A.F.; Dai, C.; Fu, G.C. Versatile catalysts for the Suzuki cross-coupling of arylboronic acids with aryl and vinyl halides and triflates under mild conditions. J. Am. Chem. Soc. 2000, 122, 4020-4028. [CrossRef]

6. Kotha, S.; Lahiri, K.; Dhurke, K. Recent applications of the Suzuki-Miyaura cross-coupling reaction in organic synthesis. Tetrahedreon 2002, 58, 9633-9695. [CrossRef]

7. Miyaura, N.; Yamada, K.; Suzuki, A. A new stereospecific cross-coupling by the palladium-catalyzed reaction of 1-alkenylboranes with 1-alkenyl or 1-alkynyl halides. Tetrahedron Lett. 1979, 20, 3437-3440. [CrossRef]

8. Johansson Seechurn, C.C.; Kitching, M.O.; Colacot, T.J.; Snieckus, V. Palladium-catalyzed cross-coupling: A historical contextual perspective to the 2010 Nobel Prize. Angew. Chem. Int. Ed. 2012, 51, 5062-5085. [CrossRef]

9. Bellina, F.; Carpita, A.; Rossi, R. Palladium catalysts for the Suzuki cross-coupling reaction: An overview of recent advances. Synthesis 2004, 15, 2419-2440. [CrossRef]

10. Wolfson, A.; Dlugy, C. Palladium-catalyzed Heck and Suzuki coupling in glycerol. Chem. Pap. 2007, 61, 228-232. [CrossRef] 
11. Nobre, S.M.; Wolke, S.I.; Da Rosa, R.G.; Monteiro, A.L. Simple and efficient protocol for catalyst recycling and product recovery in the Pd-catalyzed homogeneous Suzuki reaction. Tetrahedron Lett. 2004, 45, 6527-6530. [CrossRef]

12. Chatterjee, A.; Ward, T.R. Recent advances in the palladium catalyzed Suzuki-Miyaura cross-coupling reaction in water. Catal. Lett. 2016, 146, 820-840. [CrossRef]

13. Percec, V.; Bae, J.Y.; Hill, D.H. Aryl mesylates in metal catalyzed homocoupling and cross-coupling reactions. 2. Suzuki-type Nickel-catalyzed cross-coupling of aryl arenesulfonates and aryl mesylates with arylboronic acids. J. Org. Chem. 1995, 60, 1060-1065. [CrossRef]

14. Baghbanzadeh, M.; Pilger, C.; Kappe, C.O. Rapid Nickel-Catalyzed Suzuki-Miyaura Cross-Couplings of Aryl Carbamates and Sulfamates Utilizing Microwave Heating. J. Org. Chem. 2011, 76, 1507-1510. [CrossRef] [PubMed]

15. Zultanski, S.L.; Fu, G.C. Nickel-catalyzed carbon-Carbon bond-forming reactions of unactivated tertiary alkyl halides: Suzuki arylations. J. Am. Chem. Soc. 2013, 135, 624-627. [CrossRef] [PubMed]

16. Dong, L.; Wen, J.; Qin, S.; Yang, N.; Yang, H.; Su, Z.; Yu, X.; Hu, C. Iron-Catalyzed Direct Suzuki-Miyaura Reaction: Theoretical and Experimental Studies on the Mechanism and the Regioselectivity. ACS Catal. 2012, 2, 1829-1837. [CrossRef]

17. Hatakeyama, T.; Hashimoto, T.; Kathriarachchi, K.K.; Zenmyo, T.; Seike, H.; Nakamura, M. Iron-Catalyzed Alkyl-Alkyl Suzuki-Miyaura Coupling. Angew. Chem. Int. Ed. 2012, 51, 8834-8837. [CrossRef]

18. Fuerstner, A.; Krause, H. Practical method for the rhodium-catalyzed addition of aryl-and alkenylboronic acids to aldehydes. Adv. Synth. Catal. 2001, 343, 343-350. [CrossRef]

19. Ueura, K.; Satoh, T.; Miura, M. Rhodium-catalyzed arylation using arylboron compounds: Efficient coupling with aryl halides and unexpected multiple arylation of benzonitrile. Org. Lett. 2005, 7, 2229-2231. [CrossRef]

20. Moreau, C.; Hague, C.; Weller, A.S.; Frost, C.G. Rhodium-catalysed aryl transfer to aldehydes: Counterion effects with nitrogen containing ligands. Tetrahedron Lett. 2001, 42, 6957-6960. [CrossRef]

21. Thathagar, M.B.; Beckers, J.; Rothenberg, G. Copper-catalyzed Suzuki cross-coupling using mixed nanocluster catalysts. J. Am. Chem. Soc. 2002, 124, 11858-11859. [CrossRef]

22. Shi, S.; Nolan, S.P.; Szostak, M. Well-Defined Palladium(II)-NHC (NHC = N-Heterocyclic Carbene) Precatalysts for Cross-Coupling Reactions of Amides and Esters by Selective Acyl CO-X $(X=N, O)$ Cleavage. Acc. Chem. Res. 2018, 51, 2589-2599. [CrossRef]

23. Buchspies, J.; Szostak, M. Recent Advances in Acyl Suzuki Cross-Coupling. Catalysts 2019, 9, 53. [CrossRef]

24. Prokopcová, H.; Kappe, C.O. The Liebeskind-Srogl C-C cross-coupling reaction. Angew. Chem. Int. Ed. 2009, 48, 2276-2286. [CrossRef]

25. Ogiwara, Y.; Sakai, N. Acyl Fluorides in Late-Transition-Metal Catalysis. Angew. Chem. Int. Ed. 2020, 59, 574-594. [CrossRef] [PubMed]

26. Leadbeater, N.E.; Marco, M. Ligand-free palladium catalysis of the Suzuki reaction in water using microwave heating. Org. Lett. 2002, 4, 2973-2976. [CrossRef] [PubMed]

27. Martin, R.; Buchwald, S.L. Palladium-catalyzed Suzuki-Miyaura cross-coupling reactions employing dialkylbiaryl phosphine ligands. Acc. Chem. Res. 2008, 41, 1461-1473. [CrossRef] [PubMed]

28. Jensen, J.F.; Johannsen, M. New air-stable planar chiral ferrocenyl monophosphine ligands: Suzuki cross-coupling of aryl chlorides and bromides. Org. Lett. 2003, 5, 3025-3028. [CrossRef] [PubMed]

29. Hadei, N.; Kantchev, E.A.B.; O’Brie, C.J.; Organ, M.G. Electronic nature of N-heterocyclic carbene ligands: Effect on the Suzuki reaction. Org. Lett. 2005, 7, 1991-1994. [CrossRef]

30. Lee, D.H.; Kim, J.H.; Jun, B.H.; Kang, H.; Park, J.; Lee, Y.S. Macroporous polystyrene-supported palladium catalyst containing a bulky $\mathrm{N}$-heterocyclic carbene ligand for Suzuki reaction of aryl chlorides. Org. Lett. 2008, 10, 1609-1612. [CrossRef]

31. Marck, G.; Villiger, A.; Buchecker, R. Aryl couplings with heterogeneous palladium catalysts. Tetrahedron Lett. 1994, 35, 3277-3280. [CrossRef]

32. Paul, S.; Clark, J.H. A highly active and reusable heterogeneous catalyst for the Suzuki reaction: Synthesis of biaryls and polyaryls. Green Chem. 2003, 5, 635-638. [CrossRef]

33. Artok, L.; Bulut, H. Heterogeneous Suzuki reactions catalyzed by Pd (0)-Y zeolite. Tetrahedron Lett. 2004, 45, 3881-3884. [CrossRef]

34. Astruc, D.; Lu, F.; Aranzaes, J.R. Nanoparticles as recyclable catalysts: The frontier between homogeneous and heterogeneous catalysis. Angew. Chem. Int. Ed. 2005, 44, 7852-7872. [CrossRef] [PubMed] 
35. Desforges, A.; Backov, R.; Deleuze, H.; Mondain-Monval, O. Generation of palladium nanoparticles within macrocellular polymeric supports: Application to heterogeneous catalysis of the Suzuki-Miyaura coupling reaction. Adv. Funct. Mater. 2005, 15, 1689-1695. [CrossRef]

36. Gniewek, A.; Ziółkowski, J.J.; Trzeciak, A.M.; Zawadzki, M.; Grabowska, H.; Wrzyszcz, J. Palladium nanoparticles supported on alumina-based oxides as heterogeneous catalysts of the Suzuki-Miyaura reaction. J. Catal. 2008, 254, 121-130. [CrossRef]

37. Kerton, F.M.; Marriott, R. Alternative Solvents for Green Chemistry, 2nd ed.; Royal Society of Chemistry: Cambridge, UK, 2013.

38. Nain, S.; Singh, R.; Ravichandran, S. Importance of Microwave Heating in Organic Synthesis. Adv. J. Chem. Sect. A 2019, 2, 94-104. [CrossRef]

39. Pierluigi, B.; Liguori, F. Heterogenized Homogeneous Catalysts for Fine Chemicals Production: Materials and Processes; Springer Science \& Business Media: Berlin/Heidelberg, Germany, 2010.

40. Soni, P.L.; Soni, V. Coordination Chemistry: Metal Complexes: Transition Metal Chemistry with Lanthanides and Actinides; CRC Press: Boca Raton, FL, USA, 2013.

41. Ciriminna, R.; Pandarus, V.; Béland, F.; Pagliaro, M. Fine chemical syntheses under flow using Silia Cat catalysts. Catal. Sci. Technol. 2016, 6, 4678-4685. [CrossRef]

42. Jutz, F.; Andanson, J.M.; Baiker, A. Ionic liquids and dense carbon dioxide: A beneficial biphasic system for catalysis. Chem. Rev. 2010, 111, 322-353. [CrossRef]

43. De Wolf, E.; Van Koten, G.; Deelman, B.J. Fluorous phase separation techniques in catalysis. Chem. Soc. Rev. 1999, 28, 37-41. [CrossRef]

44. Cravotto, G.; Borretto, E.; Oliverio, M.; Procopio, A.; Penoni, A. Organic reactions in water or biphasic aqueous systems under sonochemical conditions. A review on catalytic effects. Catal. Commun. 2015, 63, 2-9. [CrossRef]

45. Gladysz, J.A. Recoverable catalysts. Ultimate goals, criteria of evaluation, and the green chemistry interface. Pure Appl. Chem. 2001, 73, 1319-1324. [CrossRef]

46. Hübner, S.; De Vries, J.G.; Farina, V. Why does industry not use immobilized transition metal complexes as catalysts? Adv. Synth. Catal. 2016, 358, 3-25. [CrossRef]

47. Martínez, A.; Krinsky, J.L.; Peñafiel, I.; Castillón, S.; Loponov, K.; Lapkin, A.; Godard, C.; Claver, C. Heterogenization of $\mathrm{Pd}-\mathrm{NHC}$ complexes onto a silica support and their application in Suzuki-Miyaura coupling under batch and continuous flow conditions. Catal. Sci. Technol. 2015, 5, 310-319. [CrossRef]

48. Vassylyev, O.; Chen, J.; Panarello, A.P.; Khinast, J.G. Catalytic properties of several supported Pd (II) complexes for Suzuki coupling reactions. Tetrahedron Lett. 2005, 46, 6865-6869. [CrossRef]

49. Kosslick, H.; Mönnich, I.; Paetzold, E.; Fuhrmann, H.; Fricke, R.; Müller, D.; Oehme, G. Suzuki reaction over palladium-complex loaded MCM-41 catalysts. Microporous Mesoporous Mater. 2001, 44, 537-545. [CrossRef]

50. Rangel, E.R.; Maya, E.M.; Sánchez, F.; De La Campa, J.G.; Iglesias, M. Palladium-heterogenized porous polyimide materials as effective and recyclable catalysts for reactions in water. Green Chem. 2015, 17, 466-473. [CrossRef]

51. Zhou, Y.B.; Li, C.Y.; Lin, M.; Ding, Y.J.; Zhan, Z.P. A Polymer-Bound Monodentate-P-Ligated Palladium Complex as a Recyclable Catalyst for the Suzuki-Miyaura Coupling Reaction of Aryl Chlorides. Adv. Synth. Catal. 2015, 357, 2503-2508. [CrossRef]

52. Mennecke, K.; Kirschning, A. Polyionic polymers-heterogeneous media for metal nanoparticles as catalyst in Suzuki-Miyaura and Heck-Mizoroki reactions under flow conditions. Beilstein J. Org. Chem. 2009, 5, 21. [CrossRef]

53. Calo, V.; Nacci, A.; Monopoli, A.; Montingelli, F. Pd nanoparticles as efficient catalysts for Suzuki and Stille coupling reactions of aryl halides in ionic liquids. J. Org. Chem. 2005, 70, 6040-6044. [CrossRef]

54. Miao, W.; Chan, T.H. Exploration of ionic liquids as soluble supports for organic synthesis. Demonstration with a Suzuki coupling reaction. Org. Lett. 2003, 5, 5003-5005. [CrossRef]

55. Giovanna, G.D.; Malinconico, M.; Laurienzo, P. Marine derived polysaccharides for biomedical applications: Chemical modification approaches. Molecules 2008, 13, 2069-2106.

56. Niaounakis, M. Biopolymers: Applications and Trends; William Andrew Books: Norwich, CT, USA, 2015.

57. Mohanty, A.K.; Misra, M.; Drzal, L.T. Natural Fibers, Biopolymers, and Biocomposites; CRC Press: Boca Raton, FL, USA, 2005. 
58. Jiao, G.; Yu, G.; Zhang, J.; Ewart, H.S. Chemical structures and bioactivities of sulfated polysaccharides from marine algae. Mar. Drugs 2011, 9, 196-223. [CrossRef]

59. McHugh, D.J. A Guide to the Seaweed Industry; FAO Fisheries Technical Paper No. 441; FAO: Rome, Italy, 2003.

60. Guo, M.Q.; Hu, X.; Wang, C.; Ai, L. Polysaccharides: Structure and Solubility. In Solubility of Polysaccharides; Xu, Z., Ed.; InTech: London, UK, 2017.

61. Campo, V.L.; Kawano, D.F.; Da Silva, D.B., Jr.; Carvalho, I. Carrageenans: Biological properties, chemical modifications and structural analysis-A review. Carbohydr. Polym. 2009, 77, 167-180. [CrossRef]

62. Necas, J.; Bartosikova, L. Carrageenan: A review. Veterinarni Medicina 2013, 58, 187-205. [CrossRef]

63. Lee, K.Y.; Mooney, D.J. Alginate: Properties and biomedical applications. Prog. Polym. Sci. 2012, 37, $106-126$. [CrossRef] [PubMed]

64. Augst, A.D.; Kong, H.J.; Mooney, D.J. Alginate hydrogels as biomaterials. Macromol. Biosci. 2006, 6, 623-633. [CrossRef]

65. Rinaudo, M. Chitin and chitosan: Properties and applications. Prog. Polym. Sci. 2006, 31, 603-632. [CrossRef]

66. Kumar, M.N.R. A review of chitin and chitosan applications. React. Funct. Polym. 2000, 46, 1-27. [CrossRef]

67. Quignard, F.; Valentin, R.; Di Renzo, F. Aerogel materials from marine polysaccharides. New J. Chem. 2008, 32, 1300-1310. [CrossRef]

68. Quignard, F.; Di Renzo, F.; Guibal, E. From natural polysaccharides to materials for catalysis, adsorption, and remediation. Top. Curr. Chem. 2010, 294, 165-197.

69. Wang, C.; Gao, X.; Chen, Z.; Chen, Y.; Chen, H. Preparation, characterization and application of polysaccharide-based metallic nanoparticles: A review. Polymers 2017, 9, 689. [CrossRef]

70. Han, H.S.; Jiang, S.N.; Huang, M.Y.; Jiang, Y.Y. Catalytic hydrogenation of aromatic nitro compounds by non-noble metal complexes of chitosan. Polym. Adv. Technol. 1996, 7, 704-706. [CrossRef]

71. Baig, R.B.N.; Varma, R.S. Copper on chitosan: A recyclable heterogeneous catalyst for azide-alkyne cycloaddition reactions in water. Green Chem. 2013, 15, 1839-1843. [CrossRef]

72. Guibal, E. Heterogeneous catalysis on chitosan-based materials: A review. Prog. Polym. Sci. 2005, 30, 71-109. [CrossRef]

73. Keshavarzipour, F.; Tavakol, H. Zinc cation supported on carrageenan magnetic nanoparticles: A novel, green, and efficient catalytic system for one-pot three-component synthesis of quinolone. Appl. Organometal. Chem. 2017, 31, e3682. [CrossRef]

74. Rostamnia, S.; Doustkhah, E.; Baghban, A.; Zeynizadeh, B. Seaweed-derived K-carrageenan: Modified $\mathrm{K}$-carrageenan as a recyclable green catalyst in the multicomponent synthesis of aminophosphonates and polyhydroquinolines. J. Appl. Polym. Sci. 2016, 133, 43190. [CrossRef]

75. Al-Matar, H.M.; Khalil, K.D.; Meier, H.; Kolshorn, H.; Elnagdi, M.H. Chitosan as heterogeneous catalyst in Michael additions: The reaction of cinnamonitriles with active methylene moieties and phenols. Arkivoc 2008, 16, 288-301.

76. Quignard, F.; Choplin, A.; Domard, A. Chitosan: A natural polymeric support of catalysts for the synthesis of fine chemicals. Langmuir 2000, 16, 9106-9108. [CrossRef]

77. Valentin, R.; Molvinger, K.; Viton, C.; Domard, A.; Quignard, F. From hydrocolloids to high specific surface area porous supports for catalysis. Biomacromolecules 2005, 6, 2785-2792. [CrossRef]

78. Vincent, T.; Guibal, E. Chitosan-supported palladium catalyst. 3. Influence of experimental parameters of nitrophenol degradation. Langmuir 2003, 19, 8475-8483. [CrossRef]

79. Cirtiu, C.M.; Dunlop-Briere, A.F.; Moores, A. Cellulose nanocrystallites as an efficient support for nanoparticles of palladium: Application for catalytichydrogenation and Heck coupling under mild conditions. Green Chem. 2011, 13, 288-291. [CrossRef]

80. Baran, $\mathrm{T} . \operatorname{Pd}(0)$ nanocatalyst stabilized on a novel agar/pectin composite and its catalytic activity in the synthesis of biphenyl compounds by Suzuki-Miyaura cross coupling reaction and reduction of o-nitroaniline. Carbohydr. Polym. 2018, 195, 45-52. [CrossRef]

81. Baran, T.; Baran, N.Y.; Mentes, A. An easily recoverable and highly reproducible agar-supported palladium catalyst for Suzuki-Miyaura coupling reactions and reduction of o-nitroaniline. Int. J. Biol. Macromol. 2018, 115, 249-256. [CrossRef] [PubMed]

82. Xu, X.; Liu, P.; Li, S.H.; Zhang, P.; Wang, X.Y. Chitosan-supported imine palladacycle complex and its catalytic performance for heck reaction. Reac. Kinet. Catal. Lett. 2006, 88, 217-223. [CrossRef] 
83. Zhou, P.; Wang, H.; Yang, J.; Tang, J.; Sun, D.; Tang, W. Bacteria Cellulose Nanofibers Supported Palladium(0) Nanocomposite and Its Catalysis Evaluation in Heck Reaction. Ind. Eng. Chem. Res. 2012, 51, 5743-5748. [CrossRef]

84. Gholinejad, M. Palladium nanoparticles supported on agarose-catalyzed Heck-Matsuda and Suzuki-Miyaura coupling reactions using aryl diazonium salts. Appl. Organomet. Chem. 2013, 27, 19-22. [CrossRef]

85. Wu, C.; Peng, X.; Zhong, L.; Li, X.; Sun, R. Green synthesis of palladium nanoparticles via branched polymers: A bio-based nanocomposite for C-C coupling reactions. RSC Adv. 2016, 6, 32202-32211. [CrossRef]

86. Baran, N.Y.; Baran, T.; Menteş, A. Production of novel palladium nanocatalyst stabilized with sustainable chitosan/cellulose composite and its catalytic performance in Suzuki-Miyaura coupling reactions. Carbohydr. Polym. 2018, 181, 596-604. [CrossRef]

87. Primo, A.; Liebel, M.; Quignard, F. Palladium coordination biopolymer: A versatile access to highly porous dispersed catalyst for suzuki reaction. Chem. Mater. 2009, 21, 621-627. [CrossRef]

88. Budarin, V.L.; Clark, J.H.; Luque, R.; Macquarrie, D.J.; White, R.J. Palladium nanoparticles on polysaccharide-derived mesoporous materials and their catalytic performance in $\mathrm{C}-\mathrm{C}$ coupling reactions. Green Chem. 2008, 10, 382-387. [CrossRef]

89. Jebali, Z.; Granados, A.; Nabili, A.; Boufi, S.; Do Rego, A.M.B.; Majdoub, H.; Vallribera, A. Cationic cellulose nanofibrils as a green support of palladium nanoparticles: Catalyst evaluation in Suzuki reactions. Cellulose 2018, 25, 6963-6975. [CrossRef]

90. Bailie, J.E.; Hutchings, G.J.; O’Leary, S. Supported Catalysts. In Encyclopedia of Materials: Science and Technology; Elsevier: Amsterdam, The Netherlands, 2001.

91. Maluenda, I.; Navarro, O. Recent developments in the Suzuki-Miyaura reaction: 2010-2014. Molecules 2015, 20, 7528-7557. [CrossRef]

92. Karimi, B.; Abedi, S.; Zamani, A. Coupling Reactions Induced by Polymer-Supported Catalysts. In Palladium-Catalyzed Coupling Reactions: Practical Aspects and Future Developments; Molnár, Á., Ed.; John Wiley \& Son: Weinheim, Germany, 2013; pp. 141-200.

93. Molnár, Á.; Papp, A. The use of polysaccharides and derivatives in palladium-catalyzed coupling reactions. Catal. Sci. Technol. 2014, 4, 295-310. [CrossRef]

94. Miller-Chou, B.A.; Koenig, J.L. A review of polymer dissolution. Prog. Polym. Sci. 2003, 28, 1223-1270. [CrossRef]

95. Árpád, M. The use of chitosan-based metal catalysts in organic transformations. Coord. Chem. Rev. 2019, 388, 126-171.

96. Guo, M.Q.; Hu, X.; Wang, C.; Lianzhong, A. Solubility of Polysaccharides. In Polysaccharides: Structure and Solubility; Xu, Z., Ed.; InTech: London, UK, 2017; pp. 7-21. ISBN 9789535136507.

97. Hardy, J.J.; Hubert, S.; Macquarrie, D.J.; Wilson, A.J. Chitosan-based heterogeneous catalysts for Suzuki and Heck reactions. Green Chem. 2004, 6, 53-56. [CrossRef]

98. Leonhardt, S.E.; Stolle, A.; Ondruschka, B.; Cravotto, G.; De Leo, C.; Jandt, K.D.; Keller, T.F. Chitosan as a support for heterogeneous Pd catalysts in liquid phase catalysis. Appl. Catal. A Gen. 2010, 379, 30-37. [CrossRef]

99. Baran, T.; Açıks̈z, E.; Menteş, A. Carboxymethyl chitosan Schiff base supported heterogeneous palladium (II) catalysts for Suzuki cross-coupling reaction. J. Mol. Catal. A Chem. 2015, 407, 47-52. [CrossRef]

100. Baran, T.; Sargin, I.; Kaya, M.; Menteş, A. An environmental catalyst derived from biological waste materials for green synthesis of biaryls via Suzuki coupling reactions. J. Mol. Catal. A Chem. 2016, 420, $216-221$. [CrossRef]

101. Baran, T.; Sargin, I.; Menteş, A.; Kaya, M. Exceptionally high turnover frequencies recorded for a new chitosan-based palladium (II) catalyst. Appl. Catal. A Gen. 2016, 523, 12-20. [CrossRef]

102. Baran, T. A new chitosan Schiff base supported Pd (II) complex for microwave-assisted synthesis of biaryls compounds. J. Mol. Struct. 2017, 1141, 535-541. [CrossRef]

103. Baran, T.; Yılmaz Baran, N.; Menteş, A. A new air and moisture stable robust bio-polymer based palladium catalyst for highly efficient synthesis of biaryl compounds. Appl. Organomet. Chem. 2018, 32, e4076. [CrossRef]

104. Baran, T.; Baran, N.Y.; Menteş, A. Highly active and recyclable heterogeneous palladium catalyst derived from guar gum for fabrication of biaryl compounds. Int. J. Biol. Macromol. 2019, 132, 1147-1154. [CrossRef] [PubMed] 
105. Baran, T.; Baran, N.Y.; Menteş, A. Preparation, structural characterization, and catalytic performance of Pd (II) and Pt (II) complexes derived from cellulose Schiff base. J. Mol. Struct. 2018, 1160, 154-160. [CrossRef]

106. Baran, N.Y.; Baran, T.; Menteş, A. Fabrication and application of cellulose Schiff base supported Pd (II) catalyst for fast and simple synthesis of biaryls via Suzuki coupling reaction. Appl. Catal. A Gen. 2017, 531, 36-44. [CrossRef]

107. Baran, T. Practical, economical, and eco-friendly starch-supported palladium catalyst for Suzuki coupling reactions. J. Colloid Interface Sci. 2017, 496, 446-455. [CrossRef]

108. Baran, T. Highly recoverable, reusable, cost-effective, and Schiff base functionalized pectin supported Pd (II) catalyst for microwave-accelerated Suzuki cross-coupling reactions. Int. J. Biol. Macromol. 2019, 127, 232-239. [CrossRef]

109. Dong, Y.; Bi, J.; Zhu, D.; Meng, D.; Ming, S.; Guo, W.; Chen, Z.; Liu, Q.; Guo, L.; Li, T. Functionalized cellulose with multiple binding sites for a palladium complex catalyst: synthesis and catalyst evaluation in Suzuki-Miyaura reactions. Cellulose 2019, 26, 7355-7370. [CrossRef]

110. Sabaqian, S.; Nemati, F.; Nahzomi, H.T.; Heravi, M.M. Palladium acetate supported on amidoxime-functionalized magnetic cellulose: Synthesis, DFT study and application in Suzuki reaction. Carbohydr. Polym. 2017, 177, 165-177. [CrossRef]

111. Lasri, J.; Mac Leod, T.C.; Pombeiro, A.J. Oxadiazoline and ketoimine palladium (II) complexes supported on a chitosan membrane and their catalytic activity for the microwave-assisted Suzuki-Miyaura cross-coupling in water. Appl. Catal. A Gen. 2011, 397, 94-102. [CrossRef]

112. Wang, X.; Hu, P.; Xue, F.; Wei, Y. Cellulose-supported N-heterocyclic carbene-palladium catalyst: Synthesis and its applications in the Suzuki cross-coupling reaction. Carbohydr. Polym. 2014, 114, 476-483. [CrossRef]

113. Chen, W.; Zhong, L.X.; Peng, X.W.; Wang, K.; Chen, Z.F.; Sun, R.C. Xylan-type hemicellulose supported palladium nanoparticles: A highly efficient and reusable catalyst for the carbon-carbon coupling reactions. Catal. Sci. Technol. 2014, 4, 1426-1435. [CrossRef]

114. Wang, X.; Xu, Y.; Wang, F.; Wei, Y. Functionalized cellulose-supported triphenylphosphine and its application in Suzuki cross-coupling reactions. J. Appl. Polym. Sci. 2015, 132, 41427. [CrossRef]

115. Levy-Ontman, O.; Biton, S.; Shlomov, B.; Wolfson, A. Renewable polysaccharides as supports for palladium phosphine catalysts. Polymers 2018, 10, 659. [CrossRef]

116. Wolfson, A.; Biton, S.; Levy-Ontman, O. Study of Pd-based catalysts within red algae-derived polysaccharide supports in a Suzuki cross-coupling reaction. RSC Adv. 2018, 8, 37939-37948. [CrossRef]

117. Wolfson, A.; Pierschel, E.; Orzehovsky, T.; Nirenberg, S.; Levy-Ontman, O. Heterogeneous iota carrageenan-based palladium catalysts for organic synthesis. Org. Commun. 2019, 12, 149-159. [CrossRef]

118. Levy-Ontman, O.; Blum, D.; Golden, R.; Pierschel, E.; Leviev, S.; Wolfson, A. Palladium Based-Polysaccharide Hydrogels as Catalysts in the Suzuki Cross-Coupling Reaction. J. Inorg. Organomet. Polym. Mater. 2019, 1-15. [CrossRef]

(C) 2020 by the authors. Licensee MDPI, Basel, Switzerland. This article is an open access article distributed under the terms and conditions of the Creative Commons Attribution (CC BY) license (http://creativecommons.org/licenses/by/4.0/). 